\title{
THE ELEGTRIGAL PROPERTIES OF SNOW AND ICE
}

\author{
By J. W. Glen and J. G. Paren \\ (Department of Physics, University of Birmingham, P.O. Box $36_{3}$, Birmingham Bi5 2 TT, \\ England)
}

\begin{abstract}
This paper reviews the electrical properties of snow and ice that are of importance in remote sensing using electrical devices. After a review of the observed laboratory behaviour of ice samples and the microscopic theory which has been advanced to explain this, the data on temperate and polar glacier ice are compared with the laboratory data. Temperate glacier ice is generally rather similar to laboratory ice, but certain relaxation processes found in the laboratory are absent from the glacier ice. Polar ice, on the other hand, is considerably different in its dielectric behaviour from "pure" laboratory ice, or temperate glacier ice; in many ways it more resembles doped laboratory ice, despite its variable, sometimes low, impurity content. It also resembles in behaviour ice produced by freezing supercooled water. The electrical behaviour of snow, and the attempts to account for this in terms of the behaviour of the ice and air components, and also of the water component in wet snow, are next discussed. Finally the implications of this work for radioecho sounding of ice, radar reflectivity from wet and dry hydrometeors, devices for determining the water content of snow, and resistivity surveys of glaciers are discussed.
\end{abstract}

RÉsumÉ. Les propriétés électriques de la neige et de la glace. Cet article passe en revue les propriétés électriques de la neige et de la glace qui sont importantes dans les méthodes de télédétection utilisant des procédés électriques. Après une revue des comportements observés au laboratoire d'échantillons de glace et des théories à l'échelle microscopique avancées pour les expliquer, on compare les résultats sur glaciers tempérés et polaires à ceux obtenus en laboratoire. La glace de glacier tempéré est généralement assez semblable à la glace de laboratoire, mais certains processus de relaxation observés en laboratoire ne se produisent pas dans la glace de glacier. Les glaciers polaires, au contraire, ont un comportement diélectrique très différent de celui de la glace "pure" de laboratoire ou de la glace de glacier tempéré; dans bien des cas, ils se rapprochent plus de la glace "dopée" en laboratoire, malgré leur teneur variable, et parfois faible, en impuretés. Ils ressemblent aussi à la glace produite par congélation d'eau surfondue. Le comportement électrique de la neige, et les tentatives pour en rendre compte à partir de celui des composants glace et air ainsi que du composant eau dans la neige mouillée, sont ensuite discutés. Finalement, on aborde les implications de ce travail pour les sondages de la glace par radio-écho, la réflectivité au radar des hydrométéores humides et secs, les procédés de détermination de la teneur en eau de la neige, et les études des glaciers par résistivité.

Zusammenfassung. Die elektrischen Eigenschaften von Schnee und Eis. Diese Arbeit gibt einen Überblick über die elektrischen Eigenschaften von Schnee und Eis, soweit sie in der Fernerkundung mit elektrischen Systemen von Bedeutung sind. Nach Schilderung des im Labor beobachteten Verhaltens von Eisproben und der mikroskopischen Theorie, die zu dessen Erklärung entwickelt wurde, werden die Daten über das Eis temperierter und polarer Gletscher mit den Laborwerten verglichen. Eis temperierter Gletscher ist im allgemeinen dem Laboreis sehr ähnlich, doch fehlen beim Gletschereis gewisse Relaxationsprozesse, die im Labor beobachtet wurden. Anderseits ist polares Eis in seinem dielektrischen Verhalten wesentlich verschieden von "reinem" Laboreis oder Eis in temperierten Gletschern; in vielfacher Hinsicht ähnelt es mehr verunreinigtem Laboreis, trotz seines veränderlichen, manchmal geringen Verunreinigungsgrades. Es ähnelt in seinem Verhalten auch dem Eis, das beim Gefrieren unterkühlten Wassers entsteht. Anschliessend wird das elektrische Verhalten von Schnee und Versuche zu seiner Erklärung aus dem Verhalten eines Gemisches aus Eis und Luft sowie der Wasserkomponente in nassem Schnee diskutiert. Schliesslich werden die Folgerungen dieser Arbeit für die Radar-Echolotung in Eis, für die Radar-Reflexion von nassen und trockenen Hydrometeoren, für Geräte zur Bestimmung des Wassergehaltes von Schnee und für Widerstandsmessungen auf Gletschern behandelt.

\section{INTRODUCTION}

Many remote-sensing devices employ electromagnetic or electrical measurements. The penetration of electromagnetic waves through ice is the basis for radio-echo sounding, and their velocity has to be known in order to interpret the data, whereas reflections from surfaces internal to the ice must be due to changes in the transmission characteristics of the ice, and their observation can be used to provide information about these changes, and consequently about the glaciological parameters which determine them. Similarly the reflection of electromagnetic waves from an ice particle, and the difference between the reflectivity of ice and water, is the basis for radar sensing of glaciation of clouds. The reflection and transmission properties of ice are also of great importance in long-distance telecommunications over glacierized areas. 
The resistivity of ice is also used for glacier depth determination by resistivity surveys, and the appropriate value for the conductivity of glacier ice is of importance in interpreting the results of such surveys. Measurement of the dielectric permittivity of ice or snow can also be used to determine the snow density or the water content of ice or snow.

Thus a proper understanding of the electrical properties of ice and snow is fundamental to the interpretation of many different remote sensing techniques, and it is for this reason that it seems appropriate to start this symposium on remote sensing in glaciology by surveying our knowledge of the electrical properties of ice and snow, particularly as samples taken from the field do seem to differ in some respects from laboratory grown specimens, and there is therefore a danger in using laboratory results in interpreting field data.

A good introduction to the physical basis for understanding the properties of ice can be found in the book by Fletcher (1970); a previous review of the dielectric properties of ice and snow has been published in this fournal by Evans (1965); this includes a chronological annotated bibliography of earlier work.

\section{TheORETIGAL UNDERSTANDING OF CONDUGTIVITY AND DIELEGTRIG DISPERSION IN ICE}

The electrical properties with which we shall be concerned are the conductivity and permittivity and their variation with frequency. The permittivity of ice is generally believed to be connected with the reorientation of water molecules, apart from a much smaller highfrequency permittivity connected with the polarizability of individual water molecules. The basis for our understanding of this reorientation permittivity is the fact that the water molecule has a relatively large dipole moment, arising from the fact that the two hydrogens in the $\mathrm{H}_{2} \mathrm{O}$ have given up their electrons to covalent bonds with the oxygen atom, and are thus positively charged, and they are situated in directions which correspond to two of the four vertices of a tetrahedron centred on the oxygen atom, while the other two vertices are the centres of electron clouds which give negative charges. There are also corresponding electron clouds surrounding the hydrogen nuclei, but these are not enough completely to neutralize the positive charge. Thus the water molecule may be thought of as having effectively four centres of electric charge, two positive and two negative, centred on the four vertices of the tetrahedron.

In the absence of an electric or stress field there will be approximately equal numbers of these tetrahedra oriented in all the possible orientations allowed by the ice structure, and so there will be no net electric dipole moment, but when a field is present it will be energetically favourable for dipoles to be aligned in a particular direction, and so the number aligned in thermal equilibrium will be determined by the statistical mechanics of the system, and this will give a permittivity to the ice provided the water molecules can in fact turn round.

The structure which ice has under normal conditions (i.e. provided pressures in excess of about I kbar are not applied, and provided the ice is not resulting from a high-pressure or vitreous form) is known as ice Ih. It has the water molecules arranged in an open hexagonal arrangement in which each water molecule has four nearest neighbours, and in which the hydrogen nuclei lie on (or very close to) the line joining two oxygen nuclei, but much nearer to one oxygen than the other. The hydrogen nuclei are not however themselves arranged crystallographically, that is to say there is no way of telling what orientation a particular water molecule will have knowing only the exact arrangement of water molecules in a region some distance away from the particular molecule in question. The hydrogen nuclei are, in other words, randomly arranged apart from the requirements (sometimes known as the Bernal-Fowler rules) that there are two hydrogens near each oxygen (i.e. that we are still dealing with $\mathrm{H}_{2} \mathrm{O}$ molecules) and that there is one hydrogen per oxygen-oxygen bond (i.e. that each bond has one centre of positive charge and one centre of negative charge on it). These rules are of course very reasonable - the first implies that water in ice is not ionized, the second arises because it is essentially the attraction between the positive charge on one water 
molecule and the negative charge on another that provides the binding force between water molecules.

If this were the whole story, however, it would be hard to understand how water molecules could turn round when an electric field is applied. For this to occur we have to consider a complication of the relatively simple picture we have given of the structure of ice. Bjerrum (195I) suggested that ice could have point defects which arise from occasional infringements of the Bernal-Fowler rules. Four distinct kinds of point defect have to be considered, two connected with each rule. If we break the first rule we could have three or one hydrogen near an oxygen instead of two- we then have $\mathrm{H}_{3} \mathrm{O}^{+}$or $\mathrm{OH}^{-}$ions respectively-we shall refer to

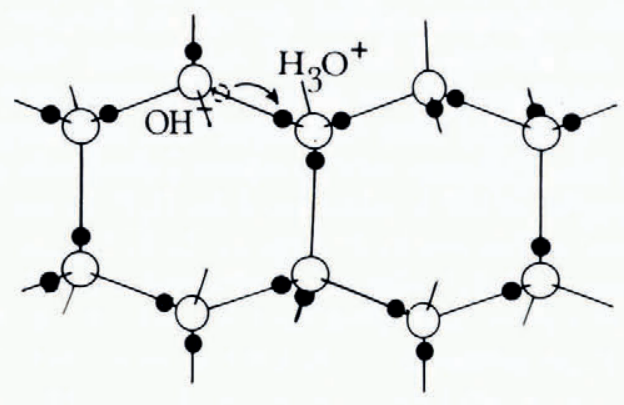

a

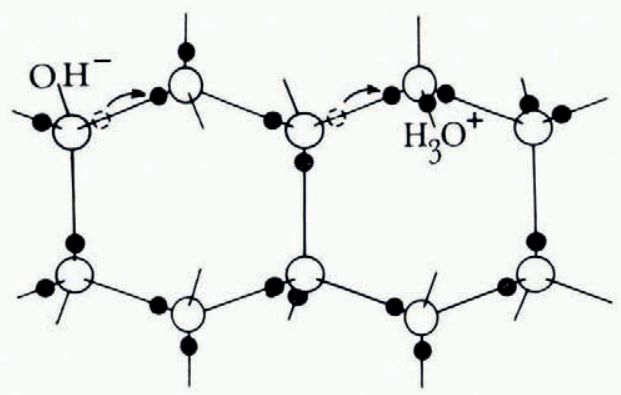

b

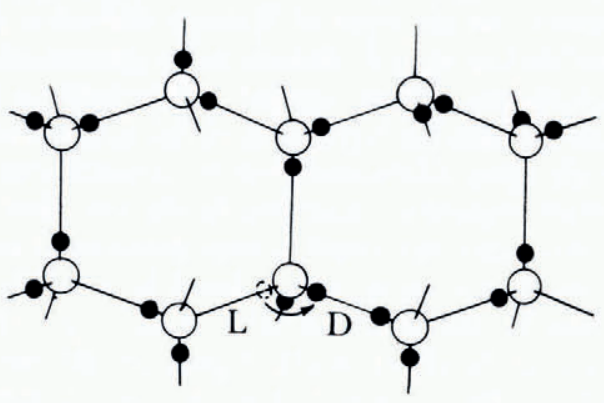

C

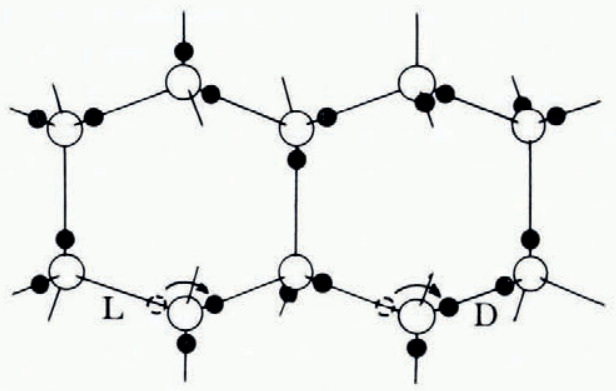

d

Fig. I. The creation and movement of electrical point defects in ice. In (a) the movement of a hydrogen nucleus from the position shown with a dashed circle creates a positive and a negative ion, and $(b)$ shows how movements of the hydrogen nucleus along a bond can make the ions migrate. (c) shows how the movement of a hydrogen nucleus around an oxygen atom can create an L-defect and a D-defect, and $(d)$ shows how this defect can also migrate by further movements around oxygen atoms. The movement of the hydrogen is to the right in all cases, but the movement of ions in $(b)$ leaves water molecules oriented with their hydrogens to the left, while the movements of $L$-and D-defects in $(d)$ leaves them with their hydrogens to the right.

these as positive and negative ionic defects. If we break the second rule we will have bonds with no or two hydrogens on (or near) them - we shall refer to these as L or D Bjerrum defects $(\mathrm{L}$ from the Danish ledig $=$ German leer $=$ vacant; $\mathrm{D}$ from the Danish dobbelt $=$ German $d o p p e l t=$ double). $\quad$ If such point defects exist, then their migration will reorient water molecules as they pass. This is shown diagrammatically in Figure I, which also shows how the defects could be created in pairs. Note how the movement of hydrogen nuclei to the right leaves water molecules oriented with their positive charges to the right for Bjerrum defect migration and to the left for ionic defect migration. Thus the presence of these defects and their migration can provide an explanation for the permittivity of ice. 
At first sight it may seem odd that the ionic defects appear to orient water molecules the wrong way round, i.e. an electric field in such a direction as to move positively charged hydrogen nuclei to the right leaves molecules aligned with their hydrogen nuclei to the left. However it must be remembered that the positively charged $\mathrm{H}_{3} \mathrm{O}^{+}$ions have all moved to the right and the negatively charged $\mathrm{OH}^{-}$ions to the left and their resulting electrical moment more than compensates for that of the molecules.

It is not necessary to have all of these defects present in ice in order to get the molecules rotated and so to get a change in dipole moment and hence a permittivity. Appreciable numbers of any one defect will do. In pure ice it is difficult to see how you could get only one sort of defect - if for example an $\mathrm{H}_{3} \mathrm{O}^{+}$ion is formed, there must be a corresponding $\mathrm{OH}^{-}$ ion somewhere - and we therefore usually think of ice as having ionic defects of both sorts present. In the case of Bjerrum defects a similar argument applies, though in this case it is possible for, say, L defects to be generated at the surface of the ice if the number of bonds sticking out of the surface which have a hydrogen nucleus on them is increased and the number with no hydrogen nuclei is decreased. A similar effect can occur with the dangling bonds along dislocations or in vacancies in the ice. Another way in which defects can arise is from impurities dissolved in the ice. For example, if $\mathrm{HF}$ is substituted for $\mathrm{H}_{2} \mathrm{O}$ in ice, it is obvious that one bond, which previously had one of the two hydrogens of the $\mathrm{H}_{2} \mathrm{O}$, now has no hydrogen, and such a bond is a ready-made L-defect with no corresponding D-defect. Similarly, the reaction $\mathrm{HF}+\mathrm{H}_{2} \mathrm{O}=\mathrm{F}^{-}+\mathrm{H}_{3} \mathrm{O}^{+}$will provide positive ionic defects. It is by studying the effect of $\mathrm{HF}$ doping on the electrical properties of ice that it has been established that the defects which dominate in ordinary ice at temperatures near the melting point are the $\mathrm{L}$ defects.

As a result of this kind of discussion, the picture we have of ice is of a material with a small number (about one in $10^{6}$ water molecules) of both $\mathrm{L}$ and $\mathrm{D}$ defects but in which the $\mathrm{L}$ defects are more mobile, and that it is their migration which enables water molecules to turn round and so respond to the presence of an external electric field, the speed of their response being governed by the number and mobility of the $\mathrm{L}$ defects, which therefore determines the relaxation time.

However ice not only has a permittivity which varies with frequency, it appears to have a resistivity even at very low frequencies (a high-frequency resistivity can result from the relaxation process referred to above when the ice cannot keep in phase with the applied electric field). In order for a conductivity to exist at low frequencies it is necessary for the charge carriers to move large distances through the ice. It is believed that the charge carriers involved are still the hydrogen nuclei, and if ionic defects are present as well as L-defects, then such conduction is possible: L-defect migration moves hydrogen nuclei round an oxygen atom; the ionic defect migration moves them along a bond. Indeed it seems that the movement of a hydrogen nucleus along a bond to move the $\mathrm{H}_{3} \mathrm{O}^{+}$ion, as shown in Figure $\mathrm{I}$, does not need any thermal activation at all, but can proceed by the quantum-mechanical tunnel effect.

This is the process which can explain the phenomenon of conduction. It is very sensitive to impurities as well, since they introduce further ionic defects, the concentration of which is very small in pure ice - indeed Von Hippel and others (1973) have questioned whether really pure ice conducts at all. The conduction is still taking place by hydrogen-ion migration, and thus, unless the electrodes can absorb or generate hydrogen, the ions will pile up at the ends of the ice and will build up a reverse electric field (the Maxwell-Wagner type of process), which will look like another, low-frequency dispersion whose magnitude depends on the specimen dimensions.

With increasing dissolved ionic impurities, the numbers of defects will change as will the energy required to liberate them, and we may even change the balance to such an extent that they exchange roles, with ionic defects becoming the majority carriers, and hence responsible for dielectric permittivity, and Bjerrum defects the minority carriers responsible for conduc- 
tion. Temperature and pressure changes also change the balance between defects, and can again bring about a change of roles. The theory has been elaborated by Jaccard (I959, I964). It predicts that the variation of dielectric permittivity with frequency will be governed by a simple dispersion with parameters determined by the conductivities resulting from the movement of Bjerrum defects and of ionic defects together with their effective charges.

Tnus from the fundamental point of view we would expect ice to show a very simple dispersion of the Debye type, the parameters for which will vary with the relative importance of Bjerrum and ionic defects, and which will therefore be affected by the presence of small amounts of dissolved impurity, and may also change significantly with temperature or pressure. The variation of relative permittivity $\epsilon$, which can be regarded as a complex quantity to take account of absorption, is discussed by Evans ( 1965 , appendix B). Through a simple dispersion $\epsilon$ varies from its low-frequency value to its high-frequency value $\epsilon_{\infty}$ according to the formula

$$
\epsilon=\epsilon_{\infty}+\frac{\Delta \epsilon}{\mathrm{I}+\mathrm{j} \omega \tau}
$$

where $\Delta \epsilon$ is the dispersion strength, $\omega$ is the angular frequency, and $\tau$ the relaxation time. When the real and imaginary components of $\epsilon$ are plotted against each other, a semi-circle results (Cole-Cole plot). The conductivity can also be regarded as a complex quantity defined as

$$
\sigma=\mathrm{j} \omega \epsilon_{0} \epsilon
$$

where $\epsilon_{0}$ is the electric constant. A semi-circle also results if the real and imaginary parts of $\left(\sigma-j \omega \epsilon_{0} \epsilon_{\infty}\right)$ are plotted against each other (Grant, 1958; Camplin and Glen, I973). The points where this plot touches the real axis correspond to the low-frequency and highfrequency limits of the conductivity and will be referred to as $\sigma_{0}$ and $\sigma_{\infty}$ for this dispersion. Their difference is related to the permittivity dispersion parameters by the equation

$$
\sigma_{\infty}-\sigma_{0}=\epsilon_{0} \Delta \epsilon / \tau \text {. }
$$

This picture is still oversimplified. In careful work Von Hippel and others (1972) have found several other dispersions in ice. These can arise from impurity effects, or from dislocations or other non-equilibrium structural defects, but it seems likely that some at least are genuine properties of pure ice. In particular the theory outlined above has not allowed for interactions between the different kinds of defects, and these could well explain the presence of an apparent high-frequency dispersion above the main Debye dispersion of the kind found by Camplin and Glen (1973).

In all the above we have ignored the crystalline structure of the ice except as providing the mechanism for reorientation. In fact since ice is hexagonal in structure, it is not to be expected that the electrical properties will be exactly the same parallel and perpendicular to the $c$-axis, although theoretically no large anisotropy is expected (Nagle, 1973); the picture we have of ice with the hydrogen atoms randomly placed consistent with the Bernal-Fowler rules in the absence of applied electric field, itself implies that there is no great difference between the differently oriented bonds, and it is on this assumption that calculations of the zero-point entropy of ice have been made which are in good agreement with experiment, so any marked anisotropy of dielectric permittivity would be hard to account for theoretically. Experimental measurements have been made by a number of workers (Humbel and others, I953; Wörz and Cole, I969; Von Hippel and others, I972; Ruepp, I973; Taubenberger, I973). There is a surprising amount of scatter in the data, even in careful experiments made with samples from the same origin, but almost all lead to the conclusion that the low-frequency permittivity of the Debye dispersion is higher parallel to the $c$-axis by some $15 \%$, an anisotropy that is difficult for the theory to explain.

The dielectric dispersion of polycrystalline ice is likely to be largely determined by the properties of the crystals of which it is composed, and we can therefore expect it to be like 
those of single crystals, and unless there is a strong preferred orientation of $c$-axes in the direction involved, to be more similar to single crystals with their $c$-axes perpendicular, and this is indeed found to be the case (Auty and Cole, 1952; Gough and Davidson, I970; Young and Salomon, I968), though Von Hippel and others (1972) find a further dispersion in their polycrystalline samples in addition to the seven they find in single crystals. A further phenomenon reported in polycrystalline ice is that specimens with relatively small thickness decrease their relaxation time on ageing for periods of the order of days (Boned and Barbier, r 973), an effect which is much more marked and more rapid than is reported for single crystals (Taubenberger, I973); the polycrystalline change in activation energy is quite dramatic, and can change from about $0.6 \mathrm{eV}$ (similar to laboratory single-crystal ice) to below $0.2 \mathrm{eV}$ a value as low as that of ice doped with $\mathrm{HF}$, for very thin samples $(0.5 \mathrm{~mm})$.

A similar reduction in activation energy has been reported for specimens made of ice droplets formed by freezing supercooled water droplets at about $-4^{1^{\circ} \mathrm{C}}$ (Evrard, I973). In this case the values of the activation energy are reported to be "quantized", that is only particular values are found all fitting the formula

$$
U_{n}=(-0.042+0.069 n) \mathrm{eV}
$$

where $n$ is an integer between 4 and 8, the two limiting values being $0.5 \mathrm{I} \mathrm{eV}$ and $0.23 \mathrm{eV}$; Evrard points out that $n=9$ would give $0.5^{8} \mathrm{eV}$, essentially the value for slowly grown, pure laboratory ice. The reason for this extraordinary behaviour is not clear, but the changes in relaxation frequency and activation energies are such that all the curves for temperature variation of relaxation frequency pass through the same value at the melting point of ice, as do the corresponding curves for the thin polycrystalline samples of Boned and Barbier (I973). It may be relevant that both the droplet samples and the very thin polycrystalline samples have been supercooled before freezing (though by very different amounts), and the authors of these papers attribute the phenomena in some way to the supercooling, and the quantization phenomena to the quantization of supercooling freczing points found by Lafargue (unpublished).

A completely different explanation of the dielectric dispersion in ice has been suggested by K. Itagaki (private communication). He attributes the dielectric dispersion to the movement of charged dislocations. In support of this he reports measurements on dislocation-free ice specimens in which the Debye dispersion is absent and higher-frequency dispersions as observed by Von Hippel alone are present. This is a very remarkable result, and if confirmed would require a radical rethinking of ice physics. Itagaki's explanation does not itself explain why normal ice specimens are as isotropic as they are, for dislocations in ice move very much more easily on the basal plane than on any other, and if they were indeed responsible for the dielectric dispersion one would expect both dispersion strength and relaxation frequency to be very much higher perpendicular to the $c$-axis.

Another quite different explanation has been proposed by Pinchukov (1970), who imagines the dielectric dispersion to be produced by hydrogen atoms moving along their bonds in the absence of defects, the relaxation time being determined by the height of the barrier to this motion. This does not seem to be likely on general chemical grounds.

The value of the dielectric permittivity at frequencies high compared with all the dispersions hitherto considered has been deduced for polycrystalline ice by Gough (1972) from measurements at frequencies up to $60 \mathrm{kHz}$ with an isolated measurement at I $\mathrm{MHz}$. With this frequency range he could make accurate measurements of $\epsilon_{\infty}$ only at temperatures lower than about $-40^{\circ} \mathrm{C}$; he finds that the asymptotic value is given by

$$
\epsilon_{\infty}=3.093 \pm 0.003+(0.72 \pm 0.60) \times 10^{-4} T+(0.1 \mathrm{I} \pm 0.02) \times \mathrm{IO}^{-5} \mathrm{~T}^{2}
$$

where $\mathcal{T}$ is the absolute temperature. Laboratory work on single crystals has not achieved the kind of consistency and accuracy of Gough's work, and is not accurate enough to indicate 
whether there is significant anisotropy of $\epsilon_{\infty}$, as has been postulated to explain changes in the polarization of radio-echoes (Harrison, 1973). The transparency of ice to V.H.F. radio waves, which makes echo-sounding possible, itself indicates that there are no significant dispersions in or near this region, and it seems likely that the next important dispersions are the well-known ones in the infra-red (see for example Whalley, r973). The theoretical explanation of this value, and its temperature dependence, is therefore to be found in the explanation of the infra-red dispersion, which is connected with relative movements of the oxygen and hydrogen nuclei. At still higher frequencies the relative movements of nuclei and electrons become important, and these are responsible for the well known anisotropy in the refractive index of ice at optical frequencies.

\section{Conductivity AND DiELEGTRIG DisPersion of NATURAL GLACIER ICE}

\section{Temperate glacier ice}

It is useful to separate discussion of electrical properties of glacier ice into two parts; the behaviour of ice in or from temperate glaciers seems to be markedly different from that of polar glaciers. Temperate glaciers are distinguished by being at or very near to the melting point. Liquid water is present, although the question of whether they are strictly at the melting point has been discussed in detail recently (Lliboutry, 1971; Paterson, 1971, 1972). There have been surprisingly few measurements of the dielectric dispersion of temperate glacier ice in situ. The only measurements to cover the main Debye dispersion with reasonably accurate technique are those of Watt and Maxwell (i96o) on the Athabasca Glacier, whose temperature characteristics have been studied in detail by Paterson (1971, 1972). They used both two-terminal bridge measurements and four-terminal a.c. conductivity measurements,

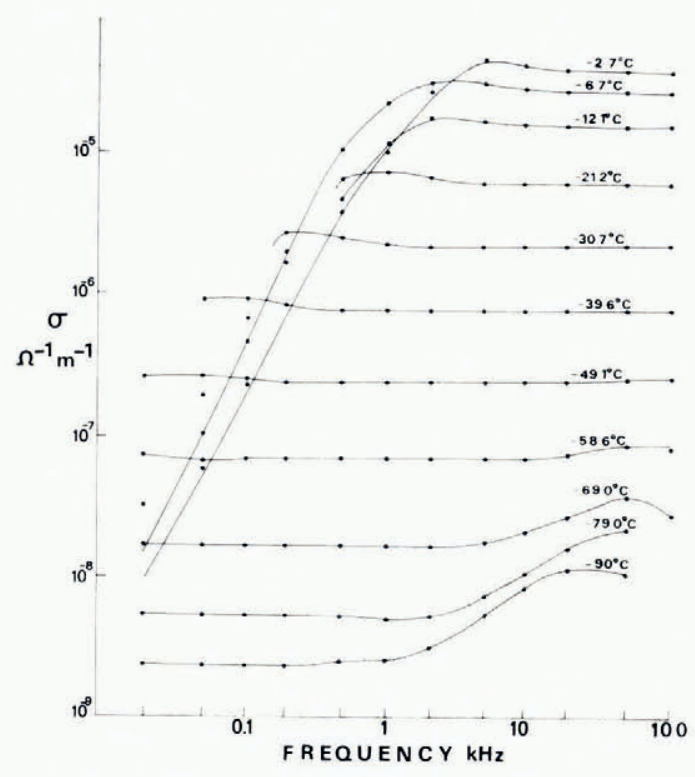

(a)

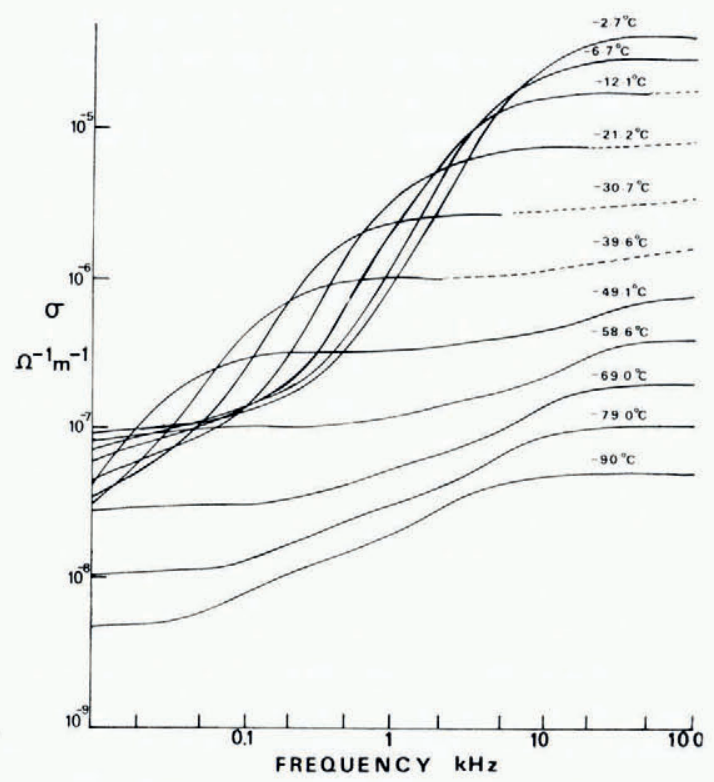

(b)

Fig. 2. The frequency dependence of the conductivity of two ice single crystals with c-axes parallel to the electric field at different temperatures. (a) shows the experimental values observed by Paren (unpublished) on a sample taken from the Mendenhall. Glacier. (b) shows values that are calculated from the "standard" polarization spectra for "pure" ice as given by fig ure I of Von Hippel and others (1972). Their spectrum o has been omitted from the calculation, and the dashed lines include contributions from their spectra 1 and 2 extrapolated to higher temperatures than those for which they observed them; if these spectra were omitted the lines would become horizontal asymptotically. 
the results of which were consistent and gave a Debye relaxation frequency which is completely consistent with that found for laboratory polycrystalline ice by Auty and Cole (1952), though they found considerable distortion of the simple Debye dispersion at low frequencies, probably associated with a d.c. conductivity of $5 \times \mathrm{IO}^{-7} \Omega^{-1} \mathrm{~m}^{-1}$. Most other work has been on samples extracted from glaciers and studied in the laboratory, particularly using the large single crystals obtained from Mendenhall Glacier. For these crystals the Debye dispersion seems to be quite similar to that for laboratory-grown single crystals, and in this case, unlike the in situ measurements, it is of course possible to study the temperature dependence and to find the activation energy of the Debye relaxation frequency (Takahashi [1968?]; Maeno, i973; Mae and Higashi, 1973; Paren, unpublished). The conductivity below the Debye dispersion deduced from these measurements by the various authors is: $4 \times 10^{-8} \Omega^{-1} \mathrm{~m}^{-1}$ at $-4^{\circ} \mathrm{C}$ (Takahashi), $2 \times 10^{-8} \Omega^{-1} \mathrm{~m}^{-1}$ independent of temperature between -10 and $-60^{\circ} \mathrm{C}$, but increasing to $4 \times 10^{-8} \Omega^{-1} \mathrm{~m}^{-1}$ after plastic deformation (Mae and Higashi), $2 \times 10^{-7} \Omega^{-1} \mathrm{~m}^{-1}$ at $-10^{\circ} \mathrm{C}$ (Paren), $2 \times 10^{-8} \Omega^{-1} \mathrm{~m}^{-1}$ at $-10^{\circ} \mathrm{C}$ with an activation energy of $0.49 \mathrm{eV}$ (Maeno). These results are therefore fairly consistent in absolute magnitude, but seriously inconsistent in temperature dependence. The main Debye dispersion however is not significantly different from that of laboratory ice crystals. However at the high-frequency end, where the laboratory specimens of Von Hippel and others (1972) show further dispersions, some of these are absent in Mendenhall crystals (Paren, unpublished). As a result the a.c. conductivity of Mendenhall crystals is much lower than that of Von Hippel and others' ice, particularly at high frequencies and low temperatures. Figure 2 shows the variation of conductivity with frequency at different temperatures for Mendenhall crystals and laboratory ice. The horizontal sections in the middle of the Mendenhall crystals diagram indicate a region separating the Debye dispersion from the high-frequency dispersion; a region that is occupied by other dispersions in Von Hippel's samples. Their absence presumably indicates an absence of dislocations, structural defects, or impurities that are present in the laboratory ice, although the impurity content of Mendenhall single crystals is higher than that of well prepared laboratory specimens. The differences between various ice specimens are also apparent in a plot of high-frequency conductivity against reciprocal temperature (Fig. 3), where it can be seen that the Mendenhall crystals continue along the Arrhenius line to lower temperatures than almost all other samples, so that if we consider deviations from this line to be the result of impurities and defects, Mendenhall crystals are seen to be among the best ice samples.

In the above discussion we have concentrated attention on the Debye dispersion and higher-frequency dispersions. If we are interested in d.c. conductivity, it is necessary to consider the lower frequency dispersions referred to above. If, as is implied by the picture we have described, these are due to the build-up of space charges in the ice, then different methods of measurement will give quite different results. In particular, if the current between two electrodes is measured as a function of the potential between those electrodes, and if the electrodes are not capable of generating or absorbing ionic defects, then a very low or even zero d.c. conductivity will be observed in ice which will nevertheless give a finite value in an experiment with electrodes capable of ionic generation and absorption or in an experiment in which current and potential probes are separate (four-electrode systems). Thus very low d.c. conductivities have been reported in certain laboratory studies, but these should not be used in, for example, electrical resistivity soundings of glaciers. In these a four-electrode measurement is made, and zero current is taken from the electrodes measuring potential, thus if a space-charge phenomenon occurs, the current electrodes will build up the space charge around themselves, the current will fall to zero, but so will the potential measured by the potential probes, and as this fall occurs the ratio will reflect the conductivity in the absence of the space-charge dispersion. In fact such measurements give conductivities from temperate glaciers from $8 \times 10^{-9}$ to $4 \times \mathrm{IO}^{-8} \Omega^{-1} \mathrm{~m}^{-1}$ (Röthlisberger and Vögtli, 1967). These compare with some of the lowest values for laboratory ice, and the lower end of the range is extremely 
small bearing in mind that the temperature is essentially $0^{\circ} \mathrm{C}$, and that temperate glacier ice has an impurity level for ionic impurities much higher than the deionized laboratory specimens.

None of the above results would seem to be affected by the small amount of water present in temperate glaciers. The in situ measurements of Watt and Maxwell (1960) did not detect the dielectric permittivity of water, the resistivity soundings gave such low values of conductivity that water impurities (which should have a high conductivity) cannot be giving a serious effect, and, of course, the samples of glacier ice tested in the laboratory were cooled, and any water in them would be frozen. However, measurements of dielectric properties in the frequency range between $\mathrm{IO}^{5}$ and $\mathrm{IO}^{8} \mathrm{~Hz}$ (Dupuy, unpublished), made on specimens immediately on being cut in the field, show an increase in a.c. conductivity with frequency at

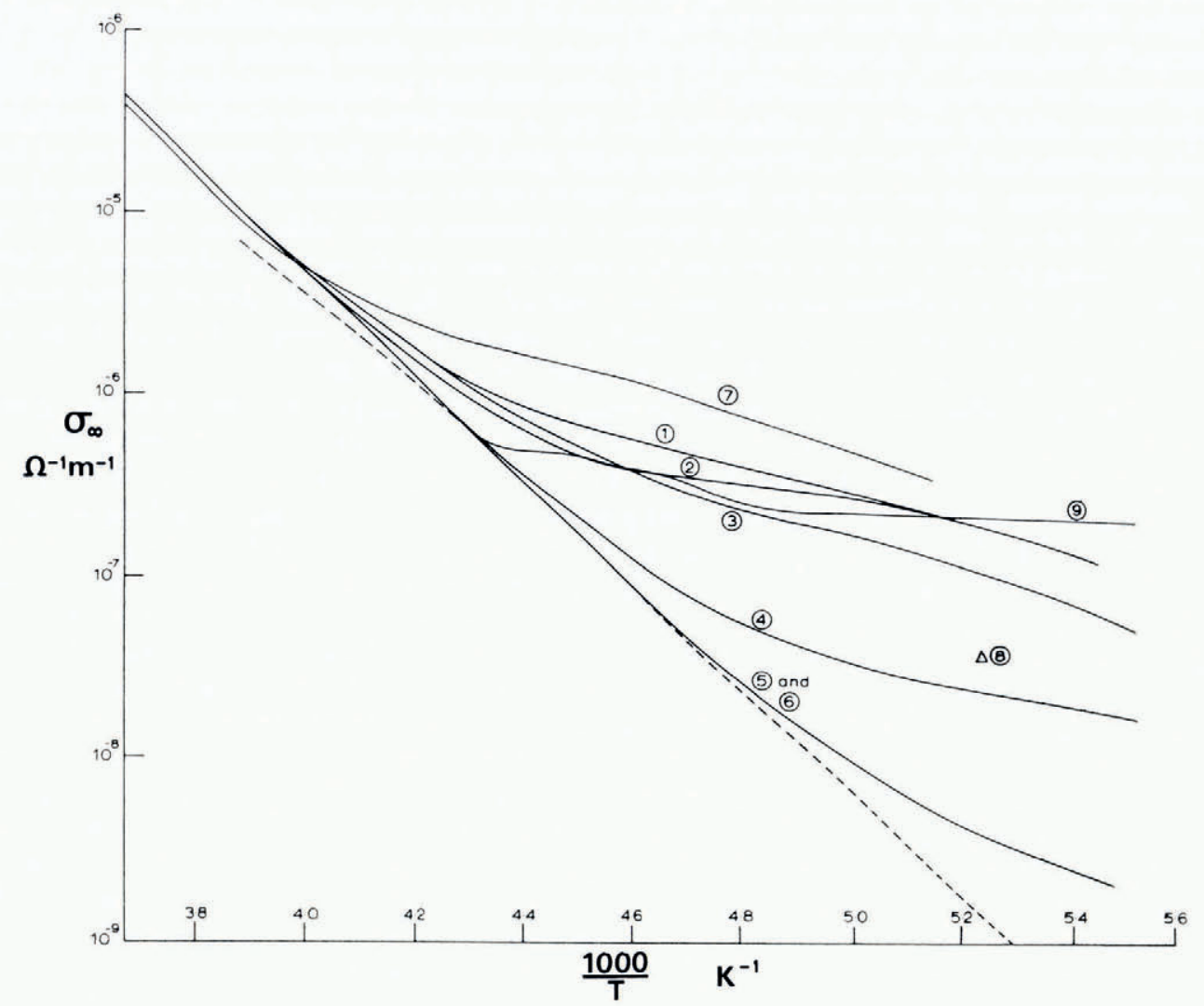

Fig. 3. Temperature dependence of the high-frequency conductivity.

I Ice from TUTO tunnel, Greenland, taken Ioo $\mathrm{m}$ from the portal (Paren, unpublished). $100 \mathrm{kHz}$.

2 Polycrystalline ice of figure II of Camp and others (I969). $20 \mathrm{kHz}$.

3 Single crystal $c \|$ to electric field. Sample $\zeta$ of Von Hippel and others (private communication in 1969 ), calculated from the parameters of the relaxation spectra.

4 Single crystal c $\perp$. R. Ruepp (private communication). $300 \mathrm{kHz}$.

5 Mendenhall Glacier single crystal $c \|$. Plateau values from Figure $2(a)$.

6 Single crystal K 70 o $\|$ of Ruepp (1973). R. Ruepp (private communication). $300 \mathrm{kHz}$.

7 Polycrystalline "commercial" ice. Paren (unpublished). $100 \mathrm{kHz}$.

8 Polycrystalline. Sample ${ }_{13} C$ of Wör $z$ and Cole $(1969)$. Calculated value at $-80^{\circ} \mathrm{C}$ from the parameters of the relaxation spectrum.

9 Mendenhall Glacier single crystal c $\|$. Mae (private communication). I $\mathrm{kHz}$. At high temperatures the value has been derived from the observed permittivity and loss at $\mathrm{I} \mathrm{kHz}$ assuming a high-frequency permittivity of 3.2. This region is dashed on the figure. 
a rate which is higher than that exhibited by the same specimens after they have been cooled, brought back to the laboratory, and rewarmed to the melting point. Dupuy attributes this to the water content in the original glacier location, and if this is correct it would imply a greater absorption of radiation in radio-echo sounding in temperate ice, compared with that deduced from the properties of ice alone.

\section{Polar glacier ice}

By polar glaciers we mean glaciers that are substantially below the melting point. There are of course intermediate cases between temperate and polar glaciers, and it is more useful to consider the various facies, as has been done by Benson ( 1967 ), who distinguishes ablation facies, wetted facies, percolation facies, and dry-snow facies. A polar glacier is one which includes either or both of the last two facies, and it is the ice in these facies that we shall be principally referring to, though ice at depth lower down a polar glacier may retain its low temperature even though it is overlain by ice which has been wetted throughout and therefore raised to the melting point. It is also true that due to geothermal heat and heat generated by plastic deformation the bottom of very deep polar glaciers may rise in temperature to or near the melting point. However in the dry-snow facies the ice is formed by consolidation of cold snow. It remains cold, and it retains a substantial amount of air, initially in bubbles, though with increasing pressure more of it dissolves in the ice and may form local volumes of clathrate structures. In the percolation facies some, but not all, of the snow is warmed to the melting point at some times; near the dry-snow line this volume may be very small and occur only in a few days each year or even only once or twice every few years.

The first indication that such ice had unusual properties compared with temperate glacier ice or laboratory ice was the unexpected discovery that in resistivity surveys using the same four-electrode technique as discussed above for temperate glaciers, the value which had to be assumed for the conductivity of the cold polar ice was orders of magnitude larger - about $10^{-5} \Omega^{-1} \mathrm{~m}^{-1}$ (Röthlisberger, ${ }^{1} 9^{6} 7$ ). Values of this order have been reported from locations in the Arctic and Antarctic and from ice sheets as well as smaller glaciers (Fig. 4). Similar results have been found for laboratory measurements of the conductivity at the low-frequency end of the Debye spectrum, and, as can be seen in Figure 4, these results are all reasonably consistent, and indicate also a temperature dependence (and hence activation energy) that is comparable with that of HF-doped ice of a similar conductivity (Camplin and Glen, I973). The electrical permittivity as a function of frequency and temperature measured in the laboratory for samples of polar ice is also similar to that of the HF-doped ice (Paren, unpublished, 1973; Fitzgerald and Paren, 1975). The variation between samples is very small. In particular the high-frequency conductivity $\sigma_{\infty}$ can be measured accurately in the laboratory, and should depend on impurity content, yet measurements from various locations (TUTO tunnel, Greenland, and Ward Hunt Ice Shelf: Westphal, reported in Ragle and others, i964, and Evans, 1965; Camp Century and Site 2, Greenland: Paren, 1973; "Byrd" station and "Mizuho", Antarctica: Maeno, 1974; "Byrd" station, Antarctica: Fitzgerald and Paren, 1975) give results which are remarkably similar, differing by little more than the errors within measurements from one source. The amount of actual impurity in these samples however varies from site to site, and is in any event small compared with the amount of HF in the laboratory-doped ice giving similar behaviour. This is an anomaly that has not yet been resolved; another paper in this symposium is devoted to it (Fitzgerald and Paren, 1975). That it is not due to the bubbles in polar ice is evidenced by similar work on anelastic damping (Kuroiwa, 1964). Here again polar ice has an activation energy lower than that of laboratory ice and temperate glacier ice, though extrapolating to similar values at the melting point, and bubbly temperate glacier ice behaved like laboratory ice, not polar ice. It is also true that deep polar core ice, with very small bubble volume, behaves just the same as more bubbly 


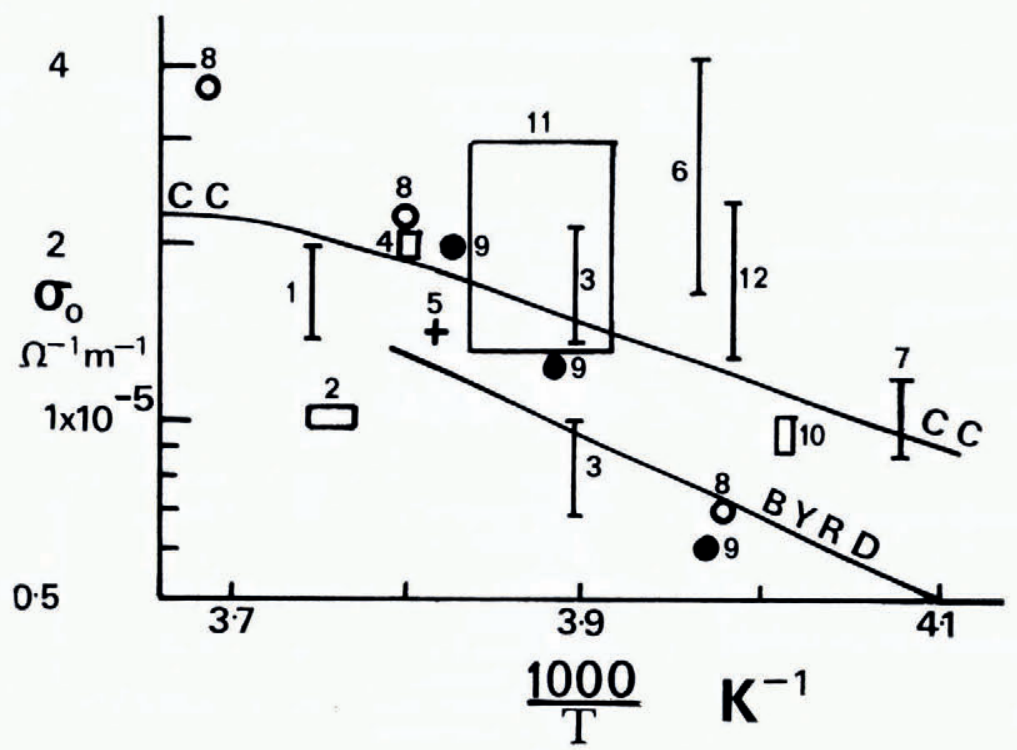

Fig. 4. Temperature dependence of the static conductivity. The laboratory measurements are shown by continuous lines; the upper, marked CC, is the mean for a deep sample from Camp Century, Greenland, (Paren, 1973); the lower is for a deep sample from "Byrd", Antarctica (Fitzgerald and Paren, 1975). Mean values for deep ice from in situ resistivity surveys are plotted with estimated uncertainties against the estimated layer temperature.

$\begin{array}{ll}\text { Andrieux (unpublished) } & \text { I. Observatory Glacier, Baffin Island } \\ & \text { 2. Penny Ice Cap, Baffin Island } \\ & \text { 3. Meighen Island ice cap } \\ & \text { 4. TUTO, Greenland } \\ \text { Clark and others }(1969) & \text { 5. Paris Gletscher, Greenland } \\ \text { Hochstein (1967) } & \text { 6. Point Nord, Greenland } \\ & \text { 7. Station Centrale, Greenland } \\ & \text { 8. Ross Ice Shelf, Antarctica } \\ \text { Meyer and Röthlisberger (I962) } & \text { 9. Roosevelt Island, Antarctica } \\ \text { Vögtli }(1967) & \text { II. Samp Century, Greenland } \\ & \text { I2. "Ice cap station, Devon Island } \\ & \end{array}$

ice from nearer the surface. It thus seems that we are dealing with a bulk property of polar ice, which must therefore have a larger concentration of ionic defects than the laboratory ice, though the reason for this is not clear. However, the consistency of these results means that, for remote sensing purposes, polar ice can be regarded as a substance with well-defined properties which, however differ from those of temperate (and laboratory pure) ice. Values of the high-frequency conductivity at $0^{\circ} \mathrm{C}$ and of the activation energy are given in Table $\mathrm{I}$. It is to be noted that the extrapolated value of $\sigma_{\infty}$ at $0^{\circ} \mathrm{C}$ is similar to that for temperate ice, it is the temperature dependence (activation energy) which differs, and this has also been noted for the ice formed from supercooled water as mentioned above. No higher frequency dispersions, of the kind found in the laboratory pure ice, have to be considered in the polar ice.

An exception to this uniformity in the behaviour of polar ice would seem to be found in some cores of lower density, corresponding to ice that is permeable (Maeno, 1973; Paren, I973) where higher conductivities are reported. These data need to be corrected to allow for the presence of air inclusions, as will be discussed below for the case of snow, but this further increases the conductivity (Table I). The activation energy of $\sigma_{\infty}$ is however similar to that of polar ice, and the phenomenon could be due to contamination of the permeable core during the drilling process. It would be very desirable to check the resistivity by in situ measurements. 
TABle I. High-FREQUENCY CONDUGTIVITY OF ICE

\begin{tabular}{|c|c|c|c|c|c|}
\hline Reference & $\begin{array}{l}\text { No. of } \\
\text { samples }\end{array}$ & $\begin{array}{l}\text { Description } \\
\text { of samples }\end{array}$ & $\begin{array}{c}\sigma_{\infty 0} \\
\mathrm{M} \Omega^{-1} \mathrm{~m}^{-1}\end{array}$ & $\begin{array}{c}\text { Activation } \\
\text { energy } \\
\mathrm{eV}\end{array}$ & $\begin{array}{c}\text { Highest frequency } \\
\text { of measurement } \\
\mathrm{MHz}\end{array}$ \\
\hline \multicolumn{6}{|l|}{ Laboratory grown single crystals } \\
\hline Camplin and Glen (1973) & I & "pure" Io. I I $\| c$ & 44 & $0.6 \mathrm{I}$ & 0.02 \\
\hline Ruepp (private communication) & I & K7o $\| c$ (of Ruepp, & 45 & 0.60 & 0.1 \\
\hline Taubenberger (1973) & I & Bi4 $\| c$ "aged" & 46 & $0.5^{6}$ & 0.3 \\
\hline \multicolumn{6}{|l|}{ Temperate glacier ice } \\
\hline Paren (1973) & I & $\begin{array}{l}\text { Mendenhall Glacier } \\
\| c\end{array}$ & 44 & 0.57 & 0.1 \\
\hline \multicolumn{6}{|l|}{ Deep polar ice } \\
\hline Westphal (private communication) \{ & I & $\begin{array}{l}\text { "Little America", } \\
\text { Antarctica }\end{array}$ & 70 & 0.17 & \\
\hline & I & $\begin{array}{l}\text { "TUTO", } \\
\text { Greenland }\end{array}$ & 45 & 0.26 & (lowest frequency) \\
\hline Westphal (quoted in Evans $\left.\left.\left(1^{9} 65\right)\right)\right\}$ & $\mathbf{I}$ & $\begin{array}{l}\text { Ward Hunt Ice } \\
\text { Shelf, Canada }\end{array}$ & 45 & 0.26 & \\
\hline Paren (1973) & I0 & $\begin{array}{l}\text { Camp Century and } \\
\text { Site 2, Greenland }\end{array}$ & $45 \pm 2$ & $0.25 \pm 0.01$ & 0.1 \\
\hline Fitzgerald and Paren (1975) & 15 & "Byrd", Antarctica & $4^{6} \pm 5$ & $0.24 \pm 0.03$ & 0.01 \\
\hline Maeno (1974) & 4 & "Mizuho", & $53 \pm 9$ & $0.24 \pm 0.02$ & 1 \\
\hline Maeno (1974) & 5 & "Byrd", Antarctica & $60 \pm 8$ & $0.23 \pm 0.01$ & I \\
\hline \multicolumn{6}{|l|}{ Permeable polar ice } \\
\hline Paren (1973) & I & $\begin{array}{l}\text { Site 2, Greenland } \\
\rho=0.78 \mathrm{Mg} \mathrm{m}^{-3}\end{array}$ & 71 & 0.21 & 0.1 \\
\hline Maeno (1973) & 5 & $\begin{array}{l}\text { "Mizuho", } \\
\text { Antarctica } \\
\rho<0.82 \mathrm{Mg} \mathrm{m}^{-3}\end{array}$ & $200 \pm 100$ & $0.20 \pm 0.02$ & I \\
\hline
\end{tabular}

All values have been corrected to solid ice density using Equation ( Io).

$\sigma_{\infty}$ is the extrapolated value of high-frequency conductivity for $0^{\circ} \mathrm{C}$ using the equation

$$
\sigma_{\infty}=\sigma_{\infty 0} \exp \left(-E\left(\mathrm{I} / T-\mathrm{I} / T_{0}\right) / k\right),
$$

an equation valid for temperatures colder than $-10^{\circ} \mathrm{C}$, where $T_{0}=273.1 \mathrm{~K}$.

It has, however, been reported that the bottom layers of polar glaciers, particularly ones that have marked glacier flow, exhibit a lower d.c. conductivity in field measurements (Meyer and Röthlisberger, I962; Clark and others, I969), and similar results have been found for ice from the TUTO tunnel, Greenland, taken $100 \mathrm{~m}$ from the portal (Paren, unpublished). This conductivity is intermediate between that of polar ice mentioned above and the temperate ice value, and could well be due to the higher temperature coupled with effects of strain, for example leading to recrystallization of the ice, which may in itself produce a change in properties, or may do this via a redistribution of impurities or bubbles.

Measurements of d.c. conductivity on the McMurdo Ice Shelf (Robertson and Macdonald, I962; Hochstein, I967) also give lower values for the d.c. conductivity. This may be due to their being nearer to the wetted facies, or to their being on ice shelf, but it is difficult to be sure in the absence of more data from other areas, and in any event measurements elsewhere on the Ross Ice Shelf (Hochstein, I967) give higher conductivities, comparable with those of polar ice (Fig. 4), and direct measurements of the conductivity of firn cores from near the surface of the McMurdo Ice Shelf (Hochstein and Risk, 1967) give still higher values, though these measurements may not have excluded surface conduction effects. 
Finally it should be mentioned that measurements of the dielectric properties of polar ice have been made using the bore hole at "Byrd" station, Antarctica (Rogers and Peden, I973), i.e. the same hole from which the samples were taken for the laboratory measurements reported above. They measured the admittance of a short dipole at five frequencies between $1.25 \mathrm{kHz}$ and $20 \mathrm{kHz}$. They find results for the complex permittivity which are in close agreement with those for pure ice at the same temperature, and which are therefore at variance with the measurements made on the samples from the core. Possible reasons for this will be discussed later in this symposium by Fitzgerald and Paren (1975).

\section{Conductivity AND DIELECTRIC DISPERSION OF SNOW AND FIRN}

The dielectric properties of dry snow should be derivable from those of ice. The dielectric behaviour of heterogeneous systems has been reviewed by Beek (1967). The simplest mixture models are those which consider spherical inclusions of one dielectric inside another. Beek shows that, on the basis of the experiments undertaken to differentiate between the accuracy of the various equations proposed for this model, there is little to choose between those of Böttcher, Bruggeman, and Looyenga.

When we are considering the structure of snow, firn, and bubbly glacier ice, we see that the concept of one dielectric forming spherical inclusions in another over the whole density range is untenable. We should rather consider air spheres in ice as a possible model for the higher density range, and ice spheres in air as a crude model for low-density snow. The equations of Böttcher and Looyenga are symmetrical between the two component permittivities $\epsilon_{1}$ and $\epsilon_{2}$, and could therefore describe the complete density range. If the volume proportion of the second dielectric is $v$, then the resultant behaviour is given by Böttcher as

$$
\frac{\epsilon-\epsilon_{1}}{3 \epsilon}=\frac{v\left(\epsilon_{2}-\epsilon_{1}\right)}{\epsilon_{2}+2 \epsilon},
$$

and by Looyenga as

$$
\epsilon^{\frac{1}{3}}-\epsilon_{1}^{\frac{1}{3}}=v\left(\epsilon_{2}^{\frac{3}{3}}-\epsilon_{1}^{\frac{1}{3}}\right) .
$$

Looyenga's equation is far easier to use than Böttcher's since there are no cross terms, and their predictions are generally very similar. When, as in our case, one dielectric is air with $\epsilon_{\mathrm{I}}=\mathrm{I}$ and the other ice with $\epsilon_{2}=\epsilon_{\mathrm{i}}$, Looyenga's equation becomes

$$
\epsilon^{\frac{1}{3}}-\mathbf{I}=v\left(\epsilon_{\left.\mathbf{i}^{\frac{1}{3}}-\mathrm{I}\right)}\right.
$$

and $v$ is now the ratio of the density of snow to that of ice.

In Figure 5 we show $\epsilon^{\frac{1}{3}}-\mathrm{I}$ plotted as a function of snow density using the data of Cumming (1952) at $9.57 \mathrm{GHz}$. The Looyenga equation predicts a straight line through the origin, and the best straight line through the points has an intercept implying a density of $0.0 \mathrm{I}_{5} \mathrm{Mg} \mathrm{m}^{-3}$ for a relative permittivity of $\mathrm{I}$, and predicts a value of 3.17 for the density $0.92 \mathrm{Mg} \mathrm{m}^{-3}$, i.e. that of ice, at $-18^{\circ} \mathrm{C}$. This value agrees with Equation (5) above.

Although these mixture equations were originally proposed for real permittivity coefficients, they can also be used with complex coefficients. This is probably justified, since they result from finding simple equations which are consistent with the deductions from electrostatic theory for the soluble problem of very dilute spherical inclusions, a theory in which it is certainly permissible to replace real permittivities by the corresponding complex ones. Hanai (r962) has also verified that Bruggeman's equation is mathematically valid for complex coefficients, and since Looyenga's equation, like Bruggeman's, is derived by integrating expressions derived from the equation for dilute spherical inclusions, it seems likely that its complex form is also valid. 
When the loss tangents of both the ice and the composite snow are small, as they will be at frequencies well above the Debye dispersion frequency of ice, then we can express the permittivity of the snow $\epsilon_{\infty}$ using the corresponding permittivity of the ice $\epsilon_{\infty i}=3.17$

$$
\epsilon \infty \mathrm{s}=(\mathrm{I}+0.469 v)^{3}
$$

which has the same form as a solution of Equation (8). We can then express the corresponding high-frequency conductivities using the imaginary part of Equation (8) as

$$
\sigma_{\infty \mathrm{s}}=\sigma_{\infty \mathrm{i}} v(0.68+0.32 v)^{2} .
$$

It is however not possible to use the real form of Equation (8) to obtain the real component of the permittivity of snow when the dielectric loss tangent is not small. In these circumstances the complex form must be used.

In the knowledge that Equation (9) represents the high-frequency permittivity of snow so well, as can be seen from Figure 5, we can now use Equation (8) or Equation (10) to compare the high-frequency conductivity of polar ice with that measured in a similar frequency range in snow. Measurements on polar snow in situ have been made by Paren (unpublished) in Axel Heiberg Island, Canada, and by Rogers (unpublished, reported by Webber and Peden, 1970; Peden and Rogers, I97 I) at "Byrd" station, Antarctica.

In Paren's experiments, two wooden sledges were equipped with metal runners, and the capacitance between them was measured for various sites on the White Glacier. The wires that connected the sledges to the capacitance bridge were raised above the glacier, and the

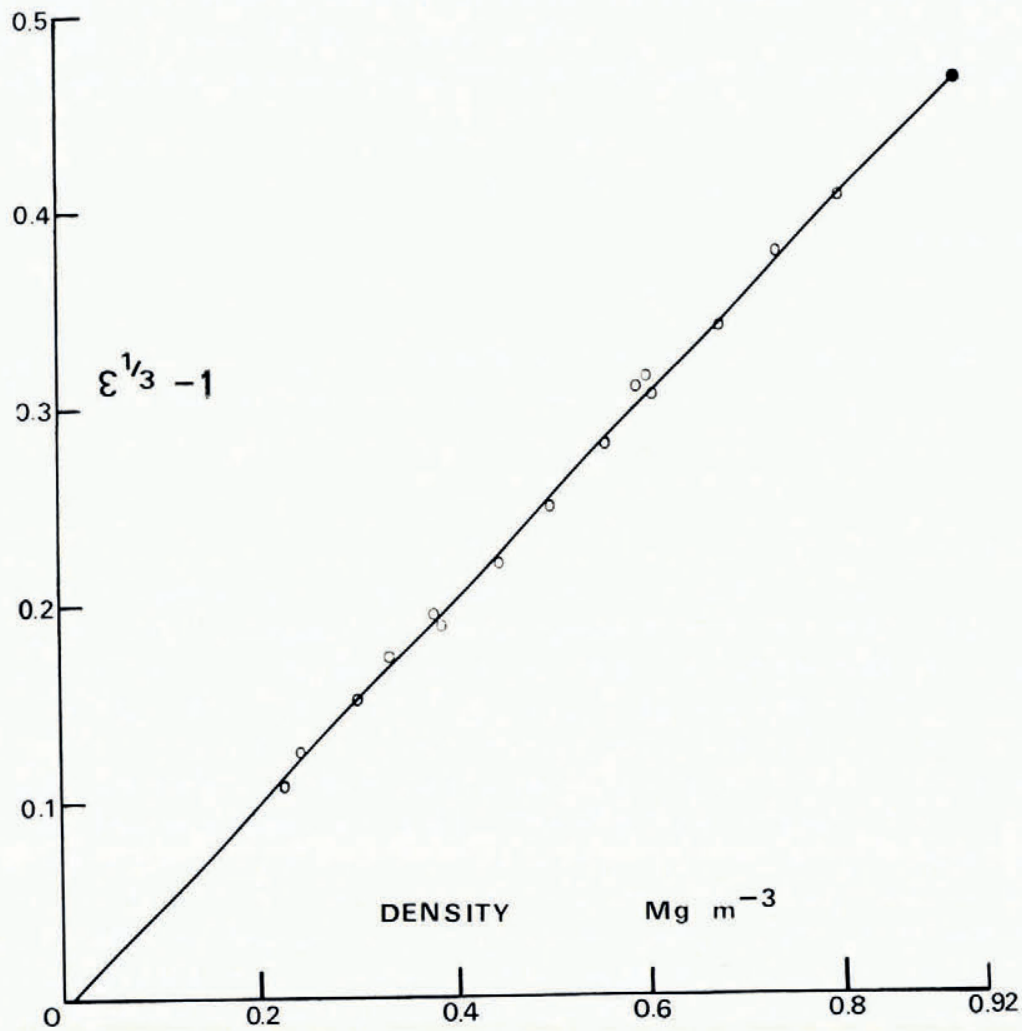

Fig. 5. Plot of $\epsilon^{\frac{1}{3}-I}$ against density for snow at $-18^{\circ} \mathrm{C}$ at $9.57 \mathrm{GHz}$ using the data of Cumming (1952). The full circle represents the value deduced from Equation (5) as well as one of Cumming's points. 
capacitance of these wires alone was measured at each frequency in a separate experiment at each site. The combined capacitance of the sledges and wires was also determined, and the capacitance between the sledges obtained by subtraction. The permittivity of the snow was then determined using the air capacitance of the electrode system as calculated by the uniformcharge method (Tagg, i964). The sledges were placed on remnant snow beds on the glacier, the density of which was measured in the course of other studies by C. S. L. Ommanney; for the sites used a density of $0.43 \pm 0.05 \mathrm{Mg} \mathrm{m}^{-3}$ is appropriate. In Figure 6 the conductivity of the snow at $20 \mathrm{kHz}$, the highest frequency used, is plotted logarithmically against the reciprocal of estimated absolute temperature of the snow surface as deduced from air temperatures measured at the base camp.

Figure 6 also shows the values found by Rogers at $10 \mathrm{kHz}$ and $12.8 \mathrm{kHz}$ at "Byrd" station on firn of density $0.4 \mathrm{Mg} \mathrm{m}^{-3}$. Both observers find a similar value for the activation energy of the conductivity in this wave band, and there is only a small difference in the magnitude of the conductivity.

These measurements can be compared with measurements made on polar ice using the theory outlined above. In Figure 7, measurements made by Paren (1973) on ice from a core from I $050 \mathrm{~m}$ depth at Camp Century, Greenland, have been used to predict via Equation

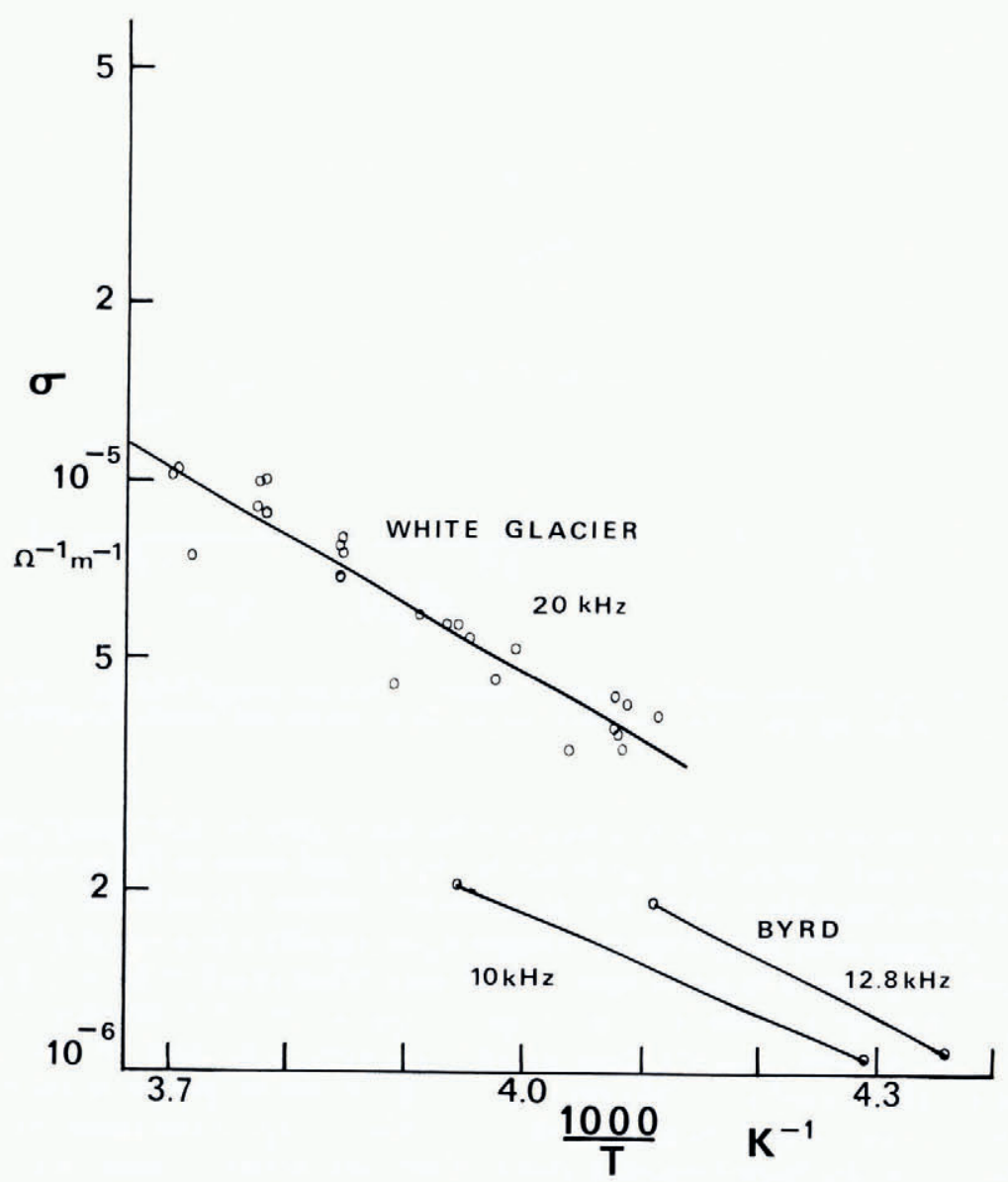

Fig. 6. Observed conductivity of polar snow plotted logarithmically against reciprocal absolute temperature. 
(8) the values to be expected for snow at the densities and frequencies corresponding to the measurements of Paren and Rogers. It can be seen that there is reasonable agreement between predictions and measurements, which would not have been achieved had the pure ice values, with their different activation energy, been used in the theory.

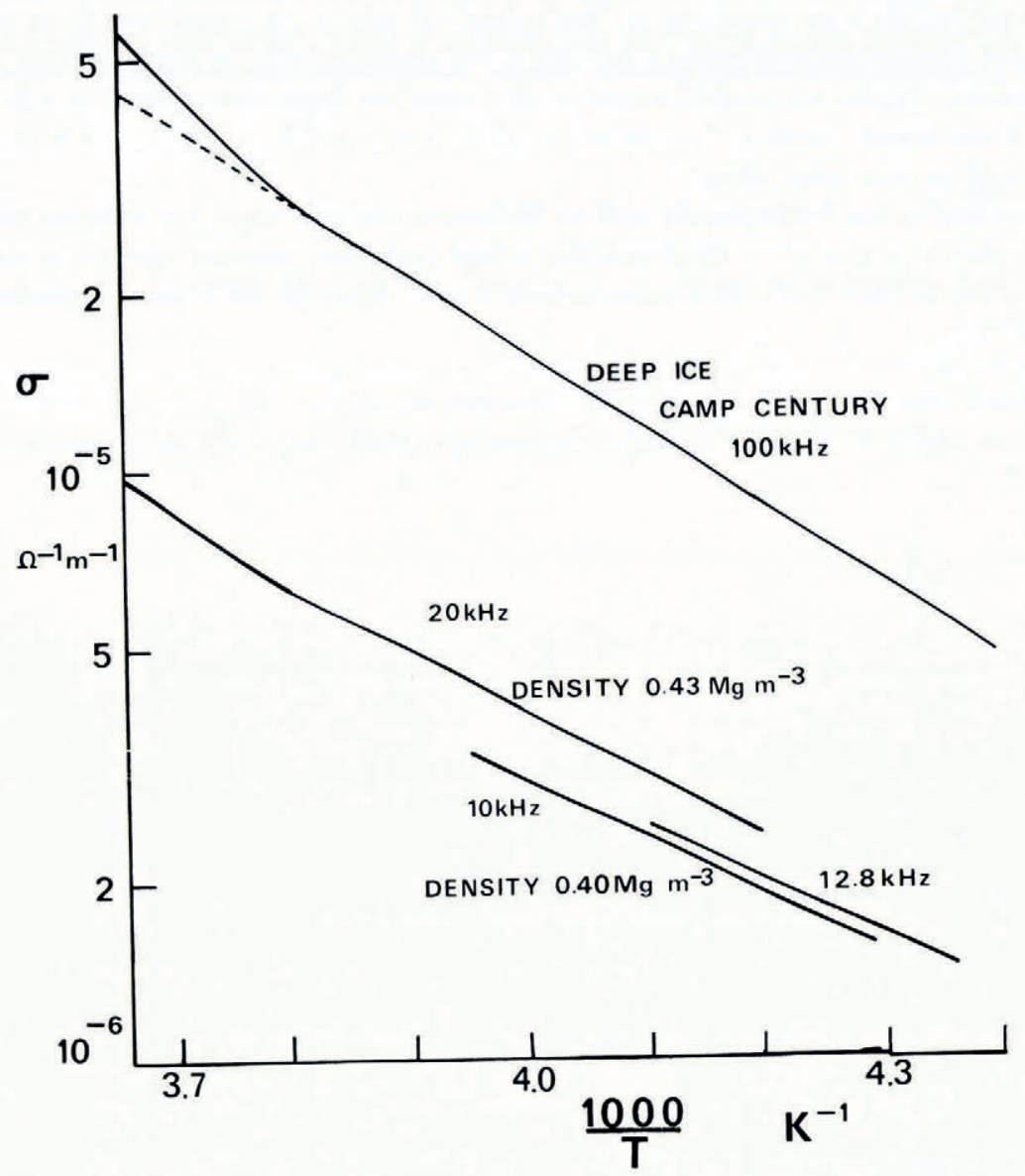

Fig. 7. Calculated conductivity of polar snow deduced using Equation (8) from the observed behaviour of deep polar ice from Camp Century, Greenland (top line). The three lower lines are for the density and frequency appropriate to the data on Figure 6.

Measurements on snow from more temperate latitudes may be more complicated due to melting processes, which can result in ice lenses or even liquid water in the snow pack. There may also be greater impurity content due to pollution. When the snow falls, particularly if this is at a low temperature, there seems no reason to distinguish it from the polar snow above, and on a temperate glacier it is such a snow which, after being raised to the melting point and infiltrated with melt water, turns into the temperate glacier ice. It is therefore of interest to try to see whether we can compare snow at various stages with polar or temperate ice as regards its dielectric properties. Unfortunately the dielectric properties of snow from temperate regions have not usually been studied over a wide temperature range so that a good activation energy for the high-frequency conductivity can result. Fujino (1967) measured snow collected in Sapporo city, but did not give information about its collection temperature 
or age; it gives an activation energy more similar to that of polar snow than that of pure ice, and also indicates the presence of a high-frequency dispersion. Most other data are for one temperature or a very limited range of temperatures, so that only a synthesis from many experiments can be used to test for the temperature dependence.

Kuroiwa (1962) has also used snow from Sapporo city, Keeler (r969) measured snow in Alta, Utah, U.S.A., and Ambach and Denoth (1972) snow in Obergurgl and from mountains near Innsbruck in the Austrian Alps. These authors generally find that there is a prominent dispersion in snow in the same frequency range in which the Debye dispersion occurs in ice. Figure 8 shows the relaxation spectra of three snows measured by Keeler (I969). The simple Debye dispersion which appears here is quite different from what is found for the polar snows discussed above, where the relatively high d.c. conductivity prevents the development of the semi-circular region of the plot. Ambach and Denoth (I972) have shown that the texture and water content of snow affect how well the dielectric behaviour agrees with a simple Debye

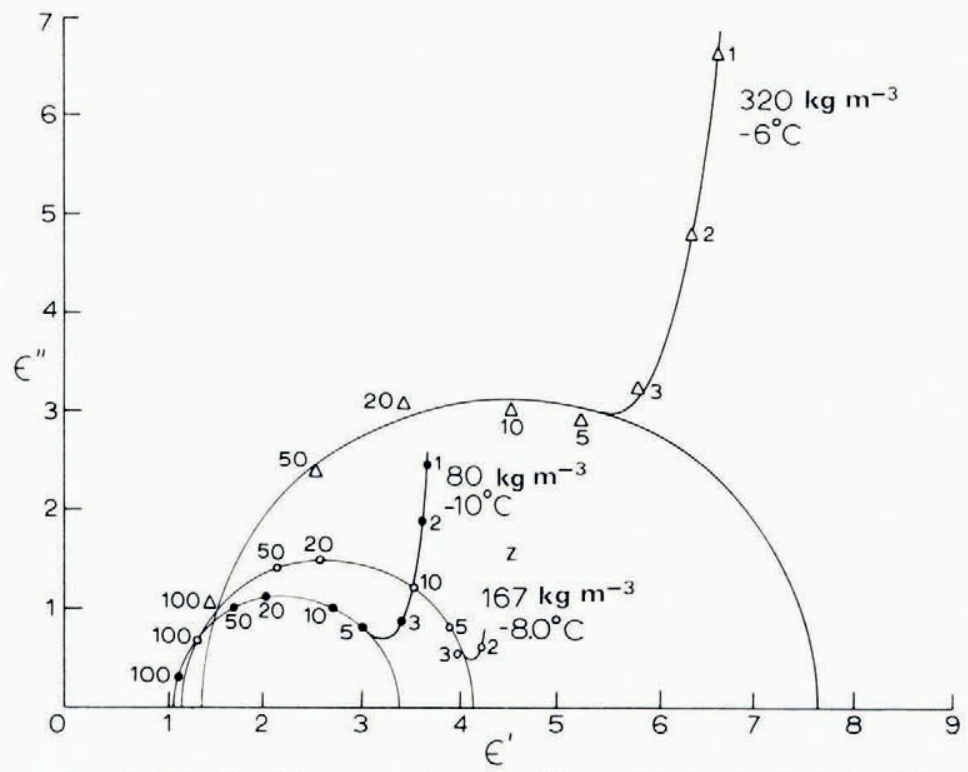

Fig. 8. Cole-Cole plot for snow from Alta, Utah, U.S.A., after Keeler (1969).

dispersion. In their figure $\mathrm{I}$ they show that a coarse-grained snow with a high water content follows the Debye formula, whereas a dry fine-grained snow gives points on a circular arc with its centre well below the $\epsilon^{\prime}$ axis, however on increasing the water content beyond o.o9 the centre of the arc approaches the $\epsilon^{\prime}$ axis and the behaviour reverts to that of the Debye formula. This effect is not yet understood, but its existence may complicate the use of dielectric measurements to determine water content unless frequencies in excess of $20 \mathrm{MHz}$ are used. The effect is unexpected, since even if the ice phase in snow obeys the simple Debye formula, Equation (8) would lead us to predict that the relaxation spectrum of snow should no longer follow the same simple formula, but that at the higher frequencies it should depart from the simple semi-circle. Figure 9 is a calculation for snow of density $0.276 \mathrm{Mg} \mathrm{m}^{-3}$, the numbers marked being the ratio of the frequency to the Debye relaxation frequency of ice. Despite this, an artificial snow sample of similar density made by Kuroiwa (1962, p. 65) showed a perfect semi-circle. The relaxation frequency found in snow samples is also more than double what would be expected from the ice mixture model, nor is the low-frequency dielectric constant 
correctly predicted if the ice value for the relative permittivity is taken as go. These failures do not depend on the particular choice of the mixture model.

If we accept that, for many snow samples, the Debye formula does in fact represent the behaviour, then we can deduce a value for the high-frequency conductivity from Equation (3) in which the d.c. conductivity, usually a very small term, can be estimated from the deviation from the semi-circle on the Cole-Cole plots at low frequencies. We can use the value of $\sigma_{\infty}$ for the snow in Equation (10) to derive a conductivity for ice. Another estimate of the highfrequency conductivity has been obtained using the highest frequency measured in the experiments concerned, deducing a value for $\sigma_{\infty}$ from this and again using Equation (I0)
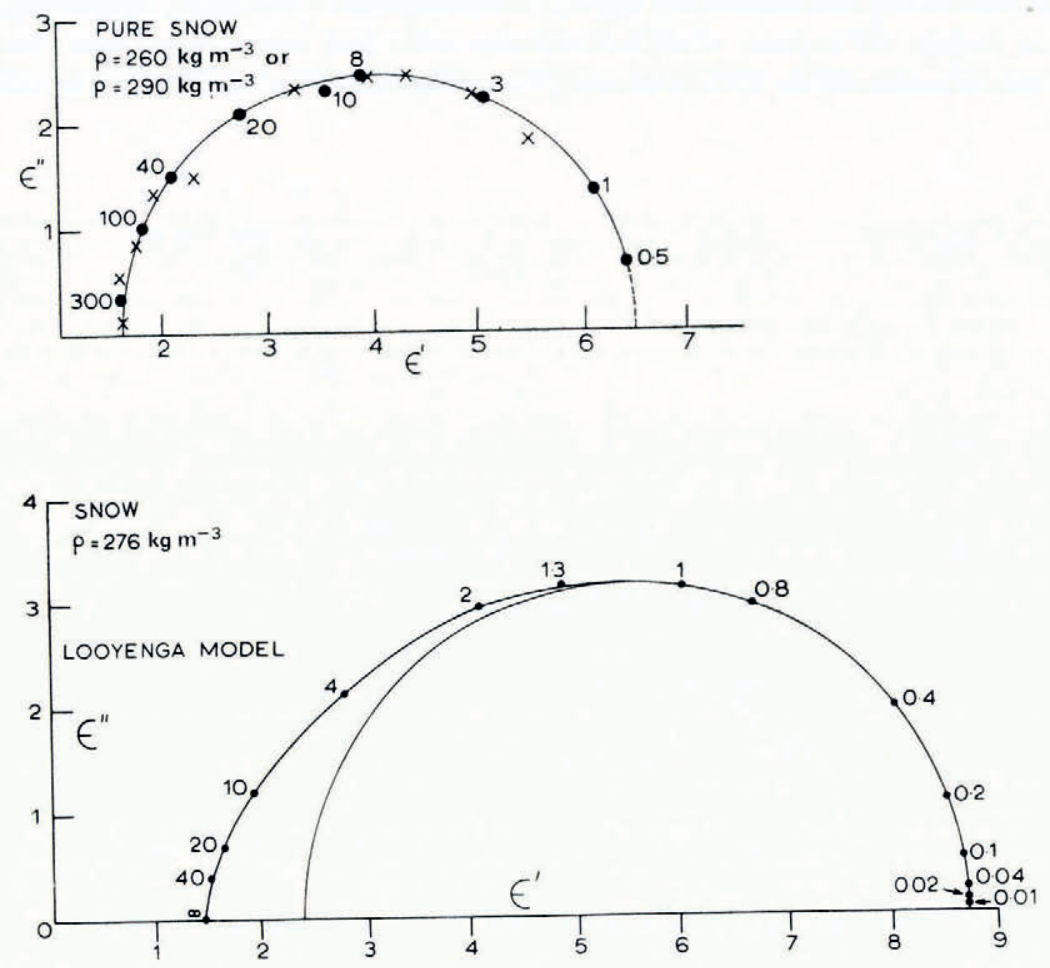

Fig. 9. Cole-Cole plot of calculated dispersion in snow (lower graph) compared with that found by Kuroiwa (1962) (upper graph). The numbers marked are frequencies in $\mathrm{kHz}$ (upper graph) and ratio of frequency to Debye relaxation frequency of ice (lower graph).

to find $\sigma_{\infty i}$. The results are shown in Figure ro. The values of the conductivity deduced from high-frequency measurements are generally higher than those predicted using the Debye formula. Lines representing the behaviour of temperate and polar glacier ice are also plotted for comparison.

The steep rise in conductivity for Kuroiwa's city snows near the melting point is probably due to impurities and the consequent presence of free water. The data generally are clearly inadequate to enable us to make a proper comparison between the behaviour of this kind of snow and that of either temperate or polar ice.

Kuroiwa (1962), Ambach (1963), Howorka (unpublished, Ambach and others, 1965), and Ambach and Denoth (1972) have used a dielectric method to provide a quick measurement of the water content of snow. All these workers have found a linear relationship between 


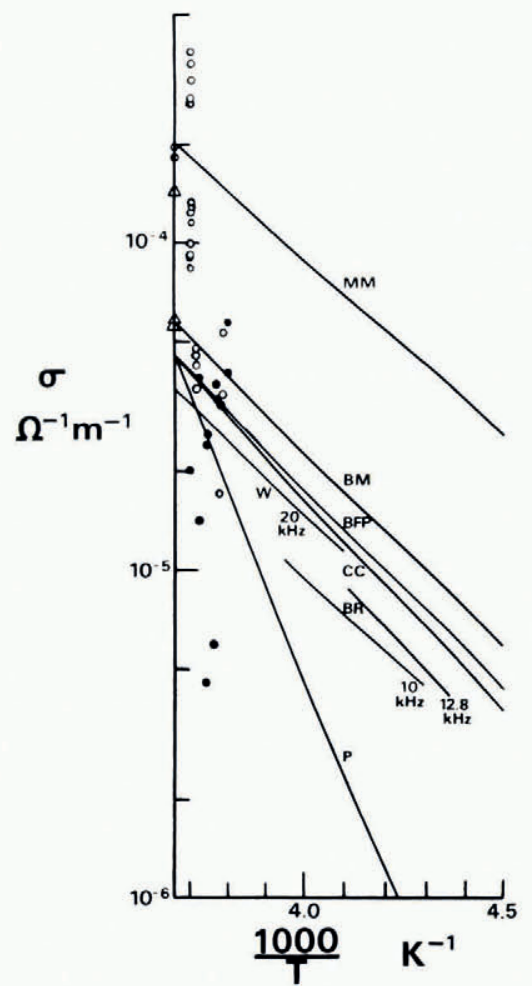

Fig. 10. Conductivity of ice deduced from data on snow plotted logarithmically against reciprocal absolute temperature,compared with data for "pure ice" $(P)$, polar ice from Camp Century, Greenland $(C C)$, "Byrd" station measured by Maeno $(B M)$ and Fitzgerald and Paren $(B F P)$. Snow data from Keeler $(\bullet)$, Kuroiwa (仓), Ambach and Denoth $(\triangle)$, Maeno from "Mizuho" (MM), Paren from White Glacier $(W)$, and Rogers from snow at "Byrd" station (BR).

dielectric permittivity $\epsilon_{\mathrm{s}}$ and water content by volume $W$, but there are differences between the absolute measurements obtained; as we have seen Ambach and Denoth (1972) suggested that higher frequencies were needed if the complicating effects of snow structure are to be avoided. Howorka's study was the most thorough; he derived the following relationship between the relative permittivity of snow, its density $\rho$ and water content $W$ at $3.5 \mathrm{MHz}$

$$
\epsilon_{\mathrm{s}}-\mathrm{I}-\left(2.22 \mathrm{~m}^{3} \mathrm{Mg}^{-1}\right) \rho=23.6 \mathrm{~W}
$$

as valid for the density range $0.12-0.40 \mathrm{Mg} \mathrm{m}^{-3}$ and water-content range $0.003-0.097$. The dry-snow values obtained by putting $W=0$ are all higher than those given by Equation (9).

Assuming that the water inclusions in the snow are not aligned in any preferred direction, we may calculate the values for $\mathrm{d} \epsilon_{\mathrm{s}} / \mathrm{d} W$ for water in the form of spheres, needles, and plates, distributed at random. The values are 6, 30 and 70 . The observed values (Table II) correspond to a mixture of spherical and less symmetrical inclusions.

TABle II. WATER-CONTENT DEPENDENCE OF THE RELATIVE PERMitTIVITY OF SNOW

Reference

Kuroiwa (1962)

Ambach (1963)

Howorka (unpublished, Ambach and others, 1965)
Location

Sapporo, Japan

Greenland, new snow

Greenland, old snow

Austria

$\begin{array}{llr}\begin{array}{c}\text { Density } \\ \mathrm{Mg} \mathrm{m}^{-3}\end{array} & \begin{array}{c}\text { Frequency } \\ \mathrm{MHz}\end{array} & \mathrm{d} \epsilon_{\mathrm{s}} / \mathrm{d} W \\ 0.5 & 3.5 & 9 . \mathrm{I} \\ 0.09 & 0.5 & 12.2 \\ 0.13 & 0.5 & 12.2 \\ 0.25-0.55 & 3.55 & 23.6\end{array}$




\section{SUMMARY OF ElEGTRICAL PROPERTIES AND THEIR RELEVANGe TO REMOTE SENSING}

We have seen above that the electrical properties of ice and snow can be described in terms of certain parameters, those of most relevance to remote sensing being the low-frequency conductivity, dispersion strength, and dispersion frequency of the Debye dispersion typically in the kilohertz range. The existence of this strong dispersion leads to absorption of electromagnetic waves in this frequency band, and the difference between the activation energy of the high-frequency conductivity as between polar ice and other ice types is a clearly established phenomenon which must be taken into account, even though the physical reason for it has not yet been clarified. There is also a difference in the shape of the dispersion between different kinds of snow which is not properly understood, although we can understand in general terms why snow, because of its admixture of air, should have a differently shaped dispersion curve. It has also been found that in careful work the dispersion in ice does not follow exactly the simple Debye law, and this can be analysed as a number of further small dispersions, some of which do not appear in certain kinds of ice. As yet this is not sufficiently well specified to be of use in remote sensing, though it may become so.

In radio-echo sounding the frequencies used are large compared with the Debye relaxation frequency, and therefore it is only the extreme high-frequency end of that dispersion which is of importance in such work. In this region the relative permittivity of all forms of solid ice are very similar, and their temperature variation is given by Equation (5), on the assumption that this formula, accurately tested at low temperatures, can be used throughout the temperature range. This leads to radio-wave velocities as given in Table III. The conductivity however does differ with the ice type, being higher in polar ice, and although it has a similar value in all ices near the melting point, the lower activation energy in polar ice leads to a much larger conductivity at the lower temperatures of polar glaciers. This should lead to a higher absorption of radio waves, nevertheless radio-echo sounding is generally easier on polar glaciers. This is due to the larger amounts of scattering in temperate glaciers, a process which tends to dominate over dielectric absorption above $8 \mathrm{MHz}$ (Strangway and others, 1974). The radioecho technique can also be used to detect discontinuities in the ice which give significant changes in the dielectric parameters over distances small compared with the pulse length (Harrison, 1973). The presence of water in an ice or snow mass can lead to large effects because of the very different dielectric response of water, and this is of course of fundamental importance in the use of radar techniques to distinguish between water and ice in hydrometeors, and in the determination of the water content of snow using frequencies in the $\mathrm{MHz}$ range.

\begin{tabular}{|c|c|c|}
\hline $\begin{array}{c}\text { Temperature } \\
{ }^{\circ} \mathrm{C}\end{array}$ & $\epsilon_{\infty}$ & $\begin{array}{l}\text { Velocity } \\
\mathrm{m} \mu \mathrm{s}^{-\mathrm{I}}\end{array}$ \\
\hline o & $3.195 \pm 0.020$ & I $67.7 \pm 0.5$ \\
\hline-20 & $3.182 \pm 0.018$ & $\mathrm{I} 68 . \mathrm{I} \pm 0.5$ \\
\hline$-4^{\circ}$ & $3.170 \pm 0.017$ & I $68.4 \pm 0.4$ \\
\hline-60 & $3.158 \pm 0.016$ & $168.7 \pm 0.4$ \\
\hline
\end{tabular}

The dielectric properties of the polar ice sheets are also of importance in considering the propagation of very low frequency (VLF) electromagnetic waves which travel in a waveguide formed by the ice sheet and the $D$ region of the polar ionosphere (Peden and others, 1972). At such frequencies the thickness of the ice sheet is small compared with the wavelength in ice, and the relevant dielectric permittivity is an average one over the whole thickness of the ice sheet. Measurements of the electromagnetic radiation from a transmitting antenna $34 \mathrm{~km}$ long embedded in the Antarctic ice sheet near "Byrd" station yield values for the complex 
relative permittivity of the ice sheet which correspond to a conductivity which is practically independent of frequency and which is similar to the high-frequency conductivity of polar ice at about $-32^{\circ} \mathrm{C}$ (or of temperate ice at about $-16^{\circ} \mathrm{C}$ ). At high frequencies this conductivity decreases, which is not the behaviour to be expected from a simple Debye dispersion, for which it should decrease at low frequencies; this may be due to the different sampling thickness at different frequencies.

Finally, the low-frequency conductivity of the Debye dispersion is what is believed to be important in resistivity soundings of glaciers, and here again the difference between polar ice and temperate ice mentioned above has to be taken into account. Indeed in this case it was the field evidence, both of the low conductivity of temperate glacier ice, and also of the difference between temperate and polar ice, that indicated to laboratory workers that their understanding of conduction in ice was not adequate.

\section{REFERENCES}

Ambach, W. 1963. Untersuchungen zum Energieumsatz in der Ablationszone des grönländischen Inlandeises (Camp IV-EGIG, $69^{\circ} 40^{\prime} 05^{\prime \prime} \mathrm{N}, 49^{\circ} 37^{\prime} 5^{\prime \prime} \mathrm{W}$ ). Meddelelser om Gronland, Bd. 174 , Nr. 4.

Ambach, W., and Denoth, A. 1972. Studies on the dielectric properties of snow. Zeitschrift für Gletscherkunde und Glazialgeologie, Bd. 8, Ht. 1-2, p. $\mathrm{II}_{3}-23$.

Ambach, W., and others. 1965 . Ein Gerät zur Bestimmung des freien Wassergehaltes in der Schneedecke durch dielektrische Messung, von W. Ambach, W. Bitterlich und F. Howorka. Acta Physica Austriaca, Bd. 20, Ht. I-4, p. $247-52$.

Andrieux, P. Unpublished. Application des méthodes électriques à l'étude de la glace et des glaciers. [Thesis Diplôme d'ingénieur géophysicien de l'Institut de Physique du Globe de Strasbourg, 1967.]

Auty, R. P., and Cole, R. H. 1952. Dielectric properties of ice and solid $\mathrm{D}_{2} \mathrm{O}$. Journal of Chemical Physics, Vol. 20, No. 8, p. ${ }^{1} 309-14$.

Beek, L. K. H. van. 1967. Dielectric behaviour of heterogeneous systems. Progress in Dielectrics, Vol. 7, p. 69-1 14.

Benson, C. S. 1967. Polar regions snow cover. (In Oura, H., ed. Physics of snow and ice: international conference on low temperature science. ... 1966. ... Proceedings, Vol. 1, Pt. 2. [Sapporo], Institute of Low Temperature Science, Hokkaido University, p. 1039-63.)

Bjerrum, N. 1951. Structure and properties of ice. Det Kongelige Danske Videnskabernes Selskab. Matematiskfysiske Meddelelser, Bd. 27, Nr. 1 .

Boned, C., and Barbier, A. 1973. A study of the change with time of the dielectric properties of polycrystalline ice. (In Whalley, E., and others, ed. Physics and chemistry of ice: papers presented at the Symposium on the Physics and Chemistry of Ice, held in Ottawa, Canada, 14-18 August 1972. Edited by E. Whalley, S. F. Fones, L. W. Gold. Ottawa, Royal Society of Canada, p. 208-11.)

Camp, P. R., and others. I 969 . Electrical conduction in ice, [by] P. R. Camp, W. Kiszenick, D. Arnold. (In Riehl, N., and others, ed. Physics of ice: proceedings of the international symposium on physics of ice, Munich, Germany, September 9-14, 1963. Edited by $\mathcal{N}$. Riehl, B. Bullemer, H. Engelhardt. New York, Plenum Press, p. 450-70.)

Camplin, G. C., and Glen, J. W. 1973. The dielectric properties of HF-doped single crystals of ice. (In Whalley, E., and others, ed. Physics and chemistry of ice: papers presented at the Symposium on the Physics and Chemistry of Ice. held in Ottawa, Canada, I4-18 August 1972. Edited by E. Whalley, S. F. Fones, L. W. Gold. Ottawa, Royal Society of Canada, p. 256-6i.)

Clark, M. C., and others. I969. Ice-resistivity measurements on Paris Gletscher, East Greenland, by M. C. Clark, M. H. Key and G. J. Pert. Journal of Glaciology, Vol. 8, No. 54, p. 369-73.

Cumming, W. A. 1952. The dielectric properties of ice and snow at 3.2 centimeters. Fournal of Applied Physics, Vol. 23 , No. 7 , p. $768-73$.

Dupuy, D. Unpublished. Étude de la glace tempérée de glacier à l'aide de mesures thermiques et diélectriques. [D. ès.-Sci. thesis, Université de Grenoble, I 970.]

Evans, S. 1965. Dielectric properties of ice and snow-a review. Fournal of Glaciology, Vol. 5, No. 42, p. $773-92$.

Evrard, G. 1973. Changes in the dielectric properties of ice formed by supercooling breakdown. (In Whalley, E., and others, ed. Physics and chemistry of ice: papers presented at the Symposium on the Physics and Chemistry of Ice, held in Ottawa, Canada, 14-18 August 1972. Edited by E. Whalley, S. J. Jones, L. W. Gold. Ottawa, Royal Society of Canada, p. 199-203.)

Fitzgerald, W. J., and Paren, J. G. 1975. The dielectric properties of Antarctic ice. Fournal of Glaciology, Vol. I5, No. 73 , p. $39-48$

Fletcher, N. H. 1970. The chemical physics of ice. Cambridge, University Press. (Cambridge Monographs on Physics.)

Fujino, K. ${ }^{1967}$. Electrical properties of sea ice. (In Ōura, H., ed. Physics of snow and ice: international conference on low temperature science. ... I966. ... Proceedings, Vol. I, Pt. I. [Sapporo], Institute of Low Temperature Science, Hokkaido University, p. 633-48.)

Gough, S. R. ${ }^{1972}$. A low temperature dielectric cell and the permittivity of hexagonal ice to 2 K. Canadian Fournal of Chemistry, Vol. 50, No. 18, p. 3046-51. 
Gough, S. R., and Davidson, D. W. 1970. Dielectric behavior of cubic and hexagonal ices at low temperatures. Fournal of Chemical Physics, Vol. 52, No. 10, p. 5442-49.

Grant, F. A. 1958. Use of complex conductivity in the representation of dielectric phenomena. Fournal of Applied Physics, Vol. 29, No. I, p. 76-8o.

Hanai, T. 1962. Dielectric theory on the interfacial polarization for two-phase mixtures. Bulletin of the Institute of Chemical Research, Kyoto University, Vol. 39, p. 34 $1-67$.

Harrison, C. H. 1973. Radio echo sounding of horizontal layers in ice. Journal of Glaciology, Vol. 12, No. 66, p. $383-97$.

Hochstein, M. P. 1967. Electrical resistivity measurements on ice sheets. Fournal of Glaciology, Vol, 6, No. 47, p. $623-33$.

Hochstein, M. P., and Risk, G. F. 1967. Determination of the activation energy of polar firn by D.C. resistivity measurements. Fournal of Glaciology, Vol. 6, No. 48, p. 91 I-I 5 .

Howorka, F. Unpublished. Dielektrische Messung des freien Wassergehalts der Schneedecke. [Dr. phil. dissertation, Universität Innsbruck, 1964.]

Humbel, F., and others. 1953. Anisotropie der Dielektrizitätskonstante des Eises, von F. Humbel, F. Jona und P. Scherrer. Helvetica Physica Acta, Vol. 26, Fasc. 1, p. 17-32.

Jaccard, C. 1959. Étude théorique et expérimentale des propriétés électriques de la glace. Helvetica Physica Acta, Vol. 32, Fasc. 2, p. 89-128.

Jaccard, C. 1964. Thermodynamics of irreversible processes applied to ice. Physik der kondensierten Materie, Bd. 3 , Ht. 2, p. $99^{-1} 18$.

Keeler, C. M. 1969 . Some physical properties of alpine snow. U.S. Cold Regions Research and Engineering Laboratory. Research Report 271.

Kuroiwa, D. 1962 . Electrical properties of snow. (In The physics and mechanics of snow as a material. U.S. Cold Regions Research and Engineering Laboratory. Cold regions science and engineering. Hanover, N.H., Pt. II, Sect. B, p. 63-79.)

Kuroiwa, D. 1964. Internal friction of ice. Contributions from the Institute of Low Temperature Science (Sapporo), Ser. A, No. 18 , p. $1-62$.

Lafargue, C. Unpublished. Limites destabilitédel'eau surfondue. [Doctorat d'État thesis, Universitéde Paris, 1952.]

Lliboutry, L. A. 1971. Permeability, brine content and temperature of temperate ice. Fournal of Glaciology, Vol. Io, No. 58, p. $15^{-29}$.

Mae, S., and Higashi, A. 1973. Effects of plastic deformation on the dielectric properties of ice. Crystal Lattice Defects, Vol. 4, No. 4, p. 295-308.

Maeno, N. 1973. Measurements of surface and volume conductivities of single ice crystals. (In Whalley, E., and others, ed. Physiss and chemistry of ice: papers presented at the Symposium on the Physics and Chemistry of Ice, held in Ottawa, Canada, 14-13 August 1972. Edited by E. Whalley, S. F. Fones, L. W. Gold. Ottawa, Royal Society of Canada, p. 140-43.)

Maeno, N. I 974 . Investigations of electrical properties of deep ice cores obtained by drilling in Antarctica. (In Kyokuchihyō shōhyō no butsuriteki kagakuteki kenkyū [Physical and chemical studies on ices [sic] from glaciers and ice sheets]. Monbushō Kagaku Kenpi Sōgō Kenkyū (A.) Hokukusho, [1973,] p. 45-56.)

Meyer, A. U., and Röthlisberger, H. 1962. Electrical D-C resistivity measurements on glacier ice near Thule, Greenland. U.S. Cold Regions Research and Engineering Laboratory. Technical Report 87.

Nagle, J. F. r 973 . Improved calculations of the dielectric constant of ice. (In Whalley, E., and others, ed. Physics and chemistry of ice: papers presented at the Symposium on the Physics and Chemistry of Ice, held in Ottawa, Canada, 14-18 August 1972. Edited by E. Whalley, S. F. Fones, L. W. Gold. Ottawa, Royal Society of Canada, p. 175-78.)

Paren, J. G. 1973. The electrical behavior of polar glaciers. (In Whalley, E., and others, ed. Physics and chemistry of ice: papers presented at the Symposium on the Physics and Chemistry of Ice, held in Ottawa, Canada, $14^{-18}$ August 1972. Edited by E. Whalley, S. 7. Jones, L. W. Gold. Ottawa, Royal Society of Canada, p. 262-67.)

Paren, J. G. Unpublished. Dielectric properties of ice. [Ph.D. thesis, University of Cambridge, r970.]

Paterson, W. S. B. 1971. Temperature measurements in Athabasca Glacier, Alberta, Canada. Fournal of Glaciology, Vol. 10, No. 6o, p. 339-49.

Paterson, W. S. B. 1972. Temperature distribution in the upper layers of the ablation area of Athabasca Glacier, Alberta, Canada. Journal of Glaciology, Vol. I I, No. 61, p. 31-41.

Peden, I. C., and Rogers, J. C. 197I. An experiment for determining the VLF permittivity of deep Antarctic ice. IEEE Transactions on Geoscience Electronics, Vol. GE-9, No. 4, p. 224-33.

Peden, I. C., and others. 1972. Complex permittivity of the Antarctic ice sheet in the VLF band, [by] I. C. Peden, G. E. Webber and A. S. Chandler. Radio Science, Vol. 7, No. 6, p. 645-50.

Pinchukov, Yu. Ye. 1970. Mezhdumolekularnyy perenos protona po vodorodnoy svyazi i dielektricheskiye svoystva kristallov l'da [Intermolecular proton transfer at the hydrogen bond and the dielectric properties of ice crystals]. Zhurnal Strukturnoy Khimii, Tom i I, No. 3, p. $4^{1} 5^{-20}$.

Ragle, R. H., and others. I964. Ice core studies of Ward Hunt Ice Shelf, r96o, by R. H. Ragle, R. G. Blair and L. E. Persson. Journal of Glaciology, Vol. 5, No. 37, p. 39-59.

Robertson, E. I., and Macdonald, W. J. P. 1962. Electrical resistivity and ground temperature at Scott Base, Antarctica. New Zealand Journal of Geology and Geophysics, Vol. 5, No. 5, p. 797-8og.

Röthlisberger, H. 1967 . Electrical resistivity measurements and soundings on glaciers: introductory remarks. Journal of Glaciology, Vol. 6, No. 47, p. 599-6o6.

Röthlisberger, H., and Vögtli, K. 1967 . Recent D.C. resistivity soundings on Swiss glaciers. Fournal of Glaciology, Vol. 6, No. 47, p. 607-21.

Rogers, J. C. Unpublished. A measurement technique for determining the VLF permittivity of deep Antarctic ice using a dipole probe. [Ph.D. thesis, University of Washington, Seattle, 1972. University Microfilms order no. 72-28655.] 
Rogers, J. C., and Peden, I. C. 1973. VLF electrical properties of the ice sheet measured at Byrd station. Antarctic Fournal of the United States, Vol. 8, No. 5, p. $241-43$.

Ruepp, R. 1973. Electrical properties of ice Ih single crystals. (In Whalley, E., and others, ed. Physics and chemistry of ice: papers presented at the Symposium on the Physics and Chemistry of Ice, held in Ottawa, Canada, 14-18 August 1972. Edited by E. Whalley, S. F. Jones, L. W. Gold. Ottawa, Royal Society of Canada, p. 1 79-86.)

Strangway, D. W., and others. 1974. Radio-frequency interferometry - a new technique for studying glaciers, by D. W. Strangway, G. Simmons, G. LaTorraca, R. Watts, L. Bannister, R. Baker, J. D. Redman and J. R. Rossiter. Journal of Glaciology, Vol. ${ }_{3}$, No. 67, p. 123-32.

Tagg, G. F. 1964. Earth resistances. London, George Newnes.

Takahashi, T. [1968?] Thermoelectric properties under the influence of impurity concentration in ice single crystals. Proceedings of the international conference on cloud physics, August 26-30, 1968, Toronto, Canada, p. 604-08.

Taubenberger, R. 1973. Aging effects of electrical properties of ice Ih single crystals. (In Whalley, E., and others, ed. Physics and chemistry of ice: papers presented at the Symposium on the Physics and Chemistry of Ice, held in Ottawa, Canada, 14-18 August 1972. Edited by E. Whalley, S. F. Fones, L. W. Gold. Ottawa, Royal Society of Canada, p. $187-93$.

Vögtli, K. 1967. D.C. resistivity soundings on Devon Island, N.W.T., Canada. Fournal of Glaciology, Vol. 6, No. 47 , p. $635-42$.

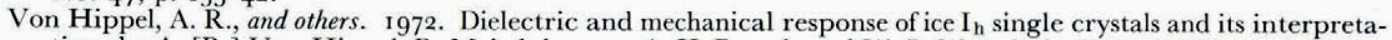
tion, by A. [R.] Von Hippel, R. Mykolajewycz, A. H. Runck and W. B. Westphal. Journal of Chemical Physics, Vol. 57, No. 6, p. 2560-71.

Von Hippel, A. R., and others. 1973. Ice chemistry: is ice Ih a proton semiconductor? [By] A. [R.] Von Hippel, A. H. Runck and W. B. Westphal. (In Whalley, E., and others, ed. Physics and chemistry of ice: papers presented at the Symposium on the Physics and Chemistry of Ice, held in Ottawa, Canada, 14-18 August 1972. Edited by E. Whalley, S. J. Fones, L. W. Gold. Ottawa, Royal Society of Canada, p. 236-41.)

Watt, A. D., and Maxwell, E. L. 1960 . Measured electrical properties of snow and glacial ice. Fournal of Research of the National Bureau of Standards (Washington, D.C.), Sect. D, Vol. 64, No. 4, p. 357-63.

Webber, G. E., and Peden, I. C. 1970. VLF ground-based measurements in Antarctica: their relationship to stratifications in the subsurface terrain. Radio Science, Vol. 5, No. 4, p. 655-62.

Whalley, E. 1973. Lattice dynamics of ice. (In Whalley, E., and others, ed. Physics and chemistry of ice: papers presented at the Symposium on the Physics and Chemistry of Ice, held in Ottawa, Canada, I4-18 August 1972. Edited by E. Whalley, S. J. Jones, L. W. Gold. Ottawa, Royal Society of Canada, p. 73-81.)

Wörz, O., and Cole, R. H. 1969 . Dielectric properties of ice I. Journal of Chemical Physics, Vol. 51, No. 4, p. $1546-50$.

Young, I. G., and Salomon, R. E. 1968. Dielectric behavior of ice with $\mathrm{HCl}$ impurity. Journal of Chemical Physics, Vol. 48, No. 4, p. I $635-44$.

\section{DISCUSSION}

S. J. Jones: As regards the anisotropy of $\Delta \epsilon$ in ice, Dr G. P. Johari and I are trying to measure this. Our preliminary results from only two samples of pure zone-refined ice, one with $c$-axis parallel and one perpendicular to the electric field, show no measurable anisotropy, that is within $2 \%$. Charette and Johari in our laboratory have also measured $\epsilon_{\infty}$ on pure polycrystalline ice at $35 \mathrm{MHz}$ above $-25^{\circ} \mathrm{C}$. At $-\mathrm{IO}^{\circ} \mathrm{C}$ they obtain $3.19 \pm 0.0 \mathrm{I}$. As regards Itagaki's dislocation explanation, Mae and Higashi (r973) have recently shown that mechanical deformation has no effect on the Debye dispersion. Do you have any comment on this?

J. Clough: In line with Dr Jones' measurements, Wörz and Cole (r969) report a value of anisotropy for the d.c. permittivity of only a few per cent rather than the $10-15 \%$ reported by Humbel and others (1953).

J. W. Glen: We have ourselves measured the Debye dispersion while straining a single crystal, and have found no effect, but I expect Dr Itagaki would say that these samples had many dislocations already which gave the dispersion. We do not believe his explanation, but I think it important that the dispersion in ice of very low dislocation density be checked. As regards the anisotropy, this new evidence, together with that of Wörz and Cole, add to the reports of low anisotropy. In our paper we wished simply to point out that several apparently careful experiments got larger anisotropy.

M. F. MeIER: Did I understand correctly that you believe it enigmatic that polar ice behaves as if it had more ionic defects than temperate ice? Perhaps one should expect that chemical impurities would be more thoroughly purged or "washed" from temperate ice, and thus less opportunity should exist for the dispersion of certain ions into the ice. 
GLEN : The problem is that actual analysis of polar ice shows it to have low ionic content compared with pure ice of similar properties and also even compared with temperate glacier ice, also the ionic content varies from place to place by amounts which would cause laboratorydoped ice to have measurably different properties, yet polar ice behaves consistently and this behaviour is like impure laboratory ice. That is the enigma.

G. DE Q. RoBIn: Do not the authors think that properties of polar firn and ice must be due to processes of metamorphosis that take place in the firn, and hence this must govern the final form of the ice, rather than it being the result of deposition through supercooling of water droplets?

GLEN: This depends on whether we think all the molecules of deep polar ice have passed through the vapour phase during metamorphosis. Even if they have, they have done it at low temperature and our remarks may still apply. I would point out that the light polar snow samples, which presumably had not undergone extensive metamorphosis, did agree with the deep polar samples after correction for density. I would agree that this means we must consider vapour deposition at low temperature as well as freezing supercooled water-that applies even to snow, presumably. 